This is a self-archived - parallel published version of this article in the publication archive of the University of Vaasa. It might differ from the original.

\title{
Robust optimization ramework for dynamic distributed energy resources planning in distribution networks
}

Author(s): Jeddi, Babak; Vahidinasab, Vahid; Ramezanpour, Parviz; Aghaei, Jamshid; Shafie-khah, Miadreza; Catalão, João P.S.

Title: $\quad$ Robust optimization ramework for dynamic distributed energy resources planning in distribution networks

Year: $\quad 2019$

Version: Accepted manuscript

Copyright Elsevier, Creative Commons Attribution Non-Commercial No Derivatives License

Please cite the original version:

Jeddi, B., Vahidinasab, V., Ramezanpour, P., Aghaei, J., Shafiekhah, M., \& Catalão, J.P.S., (2019). Robust optimization ramework for dynamic distributed energy resources planning in distribution networks. International Journal of Electrical Power and Energy Systems 110(September), 419-433. https://doi.org/10.1016/j.ijepes.2019.03.026 


\title{
Robust optimization framework for dynamic distributed energy resources planning in distribution networks
}

\author{
Babak Jeddi ${ }^{1,2}$, Vahid Vahidinasab ${ }^{1,3}$, Parviz Ramezanpour ${ }^{1}$, Jamshid Aghaei ${ }^{4}$, Miadreza Shafie-khah ${ }^{5}$, \\ João P. S. Catalão6,* \\ ${ }^{1}$ Department of Electrical Engineering, Abbaspour School of Engineering, Shahid Beheshti University, Tehran, Iran \\ ${ }^{2}$ School of Electrical Engineering and Computer Science, Queensland University of Technology, Brisbane, Australia \\ ${ }^{3}$ School of Engineering, Newcastle University, Newcastle upon Tyne, UK \\ ${ }^{4}$ Departmentof Electrical and Electronics Engineering, Shiraz University of Technology, Shiraz, Iran \\ ${ }^{5}$ School of Technology and Innovations, University of Vaasa, 65200 Vaasa, Finland \\ ${ }^{6}$ Faculty of Engineering of the University of Porto and INESC TEC, Porto 4200-465, Portugal
}

\begin{abstract}
This study relies on a dynamic reliability-based model for distributed energy resources (DER) planning in electric energy distribution networks (EEDN) with the aim of maximizing the profit of EEDN companies by increasing income and reducing costs. Load uncertainty is considered in the proposed planning model and the robust optimization (RO) approach is employed to cope with the uncertainty. The developed methodology is illustrated using real-world voltage-dependent load models, including residential, commercial and industrial types. These load models are used in evaluating the reliability cost and energy selling for customers. The reliability cost is calculated based on the total unsupplied load after an outage. Furthermore, a new modified harmony search algorithm is proposed to solve the formulated robust dynamic DER planning problem. The solution of the proposed optimization model provides the size, location, and power factor of DER. Furthermore, the need for transformers or lines upgrades and the best year for DER installation are other decision variables determined by the model. The effectiveness and capability of the developed model have been demonstrated with the aid of a case study based on a typical EEDN. The obtained results indicate that installing DER in EEDNs can relieve congestion on feeders; therefore, it can mitigate or defer upgrade investment. Moreover, if carefully planned, other benefits of DER integration such as reliability improvement and energy loss reduction can be achieved.
\end{abstract}

Keywords—Distribution networks planning; Distributed energy resources; Load uncertainty; Robust optimization; Harmony search algorithm.

\section{Nomenclature}

A. Indices

$i, u \quad$ Bus indices

$t \quad$ Year index

$j \quad$ Transformer index

$k \quad$ Substation index

$l \quad$ Feeder index

* corresponding author at the Faculty of Engineering of the University of Porto and INESC TEC, Porto 4200-465, Portugal (e-mail: catalao@fe.up.pt). 
$\Pi^{t} \quad$ Set of uncertainty for loads of network buses in year $t$

$\Lambda_{L B} \quad$ Set of network load buses

C. Parameters

$N \quad$ Life of the project (year)

$T \quad$ Planning horizon (year)

d Discount rate

$\tau \quad$ The annual rate of load growth

$\Gamma \quad$ Budget of uncertainty

$N_{\mathrm{LB}} \quad$ Total number of network load buses

$N_{\mathrm{CB}} \quad$ Number of candidate buses for DER installation

$N_{\text {SS }} \quad$ Number of existing substations

$N_{\mathrm{T}} \quad$ Number of installed transformers

$N_{\mathrm{L}} \quad$ Total number of network feeders

$N_{\mathrm{FD}} \quad$ Number of upgraded feeders

$V_{\max } \quad$ Maximum allowed operation voltage

$V_{\min } \quad$ Minimum allowed operation voltage

$p f_{\max } D E R \quad$ Maximum DER operating power factor

$p f_{\min }{ }^{D E R} \quad$ Minimum DER operating power factor

$P_{0 i}{ }^{D} \quad$ Active power demand of bus $i$ at nominal voltage

$Q_{0 i}{ }^{D} \quad$ Reactive power demand at a nominal voltage at bus $i$

$\pi_{i}^{c} \quad$ Costumer electricity price at bus $i(\$ / \mathrm{MWh})$

$\lambda_{j}{ }^{g} \quad$ Electricity market price at the substation $j(\$ / \mathrm{MWh})$

$C_{\text {upg }}{ }^{F} \quad$ Cost of feeder upgrading $(\$ / \mathrm{km})$

$C_{i}^{E N S} \quad$ Cost of energy not served at bus $i(\$ / \mathrm{MWh})$

$C_{O}{ }^{D E R} \quad$ Cost of DER operation and maintenance ( $\$ / \mathrm{MWh}$ )

$C_{k, j}{ }^{T} \quad$ Cost of installing transformer $j$ at substation $k(\$)$

$C_{\text {Inv }}{ }^{D E R} \quad$ Cost of DER installation (\$/MVA)

$S_{l}^{\max } \quad$ Maximum capacity of the feeder $l$ (MVA)

$S_{\max }{ }^{D E R} \quad$ Maximum capacity of DER (MVA)

$\mathrm{M}_{D E R} \quad$ Allowable number of installed DER

$L_{l} \quad$ Length of the feeder $l(\mathrm{~km})$

$\beta_{0} \quad$ Attractiveness coefficient

$\gamma \quad$ Light absorption coefficient

$\varphi \quad$ Randomization parameter

$s_{\mathrm{vm}} \quad$ Cartesian distance between solution vector $v$ and $m$

$\hat{\varepsilon}_{i f}^{D} \quad$ Maximum deviation of the load from the forecasted value for bus $i$ in year $t$

$\alpha \quad$ Active power exponent in voltage-dependent load model

$\beta \quad$ Reactive power exponent in voltage-dependent load model 


\begin{tabular}{|c|c|}
\hline \multicolumn{2}{|c|}{ D. Variables } \\
\hline$P_{i}^{D}, Q_{i}^{D}$ & Active and reactive power demand at bus $i$ \\
\hline $\operatorname{Inv} C$ & Investment cost of the network (\$/year) \\
\hline OprC & Operation cost of the network (\$/year) \\
\hline $\operatorname{RelC}$ & Reliability cost of the network (\$/year) \\
\hline $\bar{P}_{0 i, t}^{D}$ & Forecasted active power demand at bus $i$ in year $t$ (MW) \\
\hline$S_{u}{ }^{D E R}$ & Capacity of installed DER at bus $u$ (MVA) \\
\hline$P_{j}^{\text {grid }}$ & Active power imported from the grid by the substation $j(\mathrm{MW})$ \\
\hline$V_{i}$ & Voltage magnitude of bus $i$ \\
\hline$p f_{u}^{D E R}$ & Power factor of installed DER at bus $u$ \\
\hline$S_{l}$ & Transmitted power in the feeder $l$ \\
\hline$\varepsilon_{i, t}^{D}$ & Load deviation from the forecasted value for bus $i$ in year $t$ \\
\hline rand $)$ & Random number uniformly between 0 and 1 \\
\hline \multicolumn{2}{|c|}{ E. Abbreviations } \\
\hline ENS & Energy not served \\
\hline$H M$ & Harmony matrix \\
\hline$H M S$ & Harmony memory size \\
\hline$H M C R$ & Harmony memory consideration rate \\
\hline$P A R$ & Pitch adjustment rate \\
\hline$B W$ & Bandwidth \\
\hline$U B$ & Upper bound of optimization variable \\
\hline$L B$ & Lower bound of optimization variable \\
\hline
\end{tabular}

\section{Introduction}

\subsection{Motivation and background}

Electrical energy distribution networks (EEDNs) are the final stage in delivering a reliable and faultless electric energy supply to end-users, and accordingly, expansion planning of electrical energy distribution networks (EDNEP) is one of the most important problems in electric power system [1]. On the other hand, EEDNs are the main recipient of all the new interactions resulting from the increasing penetration of distributed energy resources (DER) and the arrival of novel technologies facilitating demand response programs. End users can take advantage of the new options provided by DER, smart metering devices, and communication infrastructures. Traditionally, EDNEP was performed by building new substations, adding new transformers to the existing substations, and upgrading the network feeders. Nevertheless, with the increasing penetration of DERs in today's EEDNs, distribution companies (DISCOs) have learnt another way of meeting the rising load growth. Therefore, the EDNEP problem has changed with the arrival of DER. The main benefits of the DER utilization are loss reduction, deferral of transmission and EEDN reinforcement, voltage profile improvement, network reliability, and power quality [2]. Provided that an appropriate planning scheme is designed, all of these advantages can be achieved. Hence, this study models the EDNEP problem in the presence of DER with the aim of maximizing above-mentioned benefits taking into account the load uncertainty. 


\subsection{Literature review}

In general, the EDNEP problem can be investigated from four major aspects including timing, problem formulation, solution method, and uncertainty handling. From the timing point of view, there are two commonly used approaches for solving the EDNEP problem: static planning [3] and dynamic planning [4]. The static planning approach determines the optimal location, type, and capacity of equipment to be expanded and/or installed at the beginning of the planning horizon. On the other hand, the dynamic planning approach not only considers the expansion and/or installation, but also defines the best time to make such investments. Although the dynamic planning approach makes the EDNEP problem more complex and harder to solve, it has the advantage of investment savings and better technical responses. Moreover, in the dynamic planning approach, the investment cost has a slow annual growth, but in the static planning approach, the whole investment needs to be made at the beginning of the project. From the problem formulation viewpoint, the EDNEP problem is solved considering different objective functions mainly including minimizing network investment and operational costs, minimizing network losses, minimizing pollution emission, and improving the voltage profile. Regarding the benefits of DER, reliability improvement can also be included in the problem formulation which requires choosing appropriate indices and modelling network for reliability calculations. Furthermore, it has been shown that considering voltage-dependent load models in power flow calculations in the optimal DER planning problem can significantly affect the results $[5,6]$. From the solution method standpoint, various techniques have been applied to optimize objective functions which can be divided into three main groups namely mathematical optimization, heuristic methods, and meta-heuristic algorithms. Mathematical optimization techniques, such as linear programming (LP), have a high computational cost and also require some simplifications on the problem formulation, and therefore, their application is limited. On the other hand, heuristic methods and meta-heuristic algorithms, such as genetic algorithm (GA), are faster and require few or no simplifications about the problem. Therefore, they have been more popular for solving the EDNEP problem.

Finally, from the uncertainty perspective, the EDNEP problem faces several uncertainties related to DER production, load and electricity price which need to be incorporated to improve the planning efficiency. The most commonly used methods to deal with the uncertainties are: fuzzy method [7], point estimate method [8], scenario-based modeling [9, 10], interval numbers [11], chance-constrained programming [12], and Monte Carlo simulation [13]. However, most of these methods are inherently complex and numerically intractable models for realistic power systems. The complexity of these methods originates from this fact that they require probability density functions of the uncertain variables to be built which may not be straightforward for many real-world systems. Moreover, a large number of scenarios are needed to obtain a high-quality solution leading to a computationally intractable approach. Furthermore, the optimal solution is only feasible for the generated scenarios. These methods are also unable to control the conservation level of the optimal investment strategy. Another approach for decision making under uncertainty is robust optimization (RO), which models uncertainties by means of a set of deterministic and bounded intervals $[14,15]$. The RO method solves a deterministic form of the initial non-deterministic problem, called the robust counterpart, to obtain an optimal solution which is immunized against uncertain parameters. This is the important characteristic of the RO model which makes it computationally tractable even for medium or large scale problems. Also, it does not require the probability distribution function of the uncertain parameter. This approach has received growing attention in various fields of power system optimization [16-18].

In the following, some recently published studies in DER planning are discussed considering the above-mentioned four aspects. In [19] a GA based static approach is proposed for the optimal DER allocation in EEDNs, to minimize network losses and ensure an acceptable reliability level as well as the voltage profile. The benefit of DER on reliability indices is effectively analyzed, however, voltage-dependent load models and uncertainties are not included in this study. Artificial bee colony 
algorithm is another approach utilized in [19] to decide on the optimal size, power factor, and location of DER. The impacts of proper installation of DER on system loss is investigated, but the reliability impact and uncertainties are ignored. Reference [20], without considering uncertainties, introduces a static multi-objective approach based on the shuffled frog leaping algorithm for optimal DER planning to control losses, energy cost, and pollutant emissions simultaneously. An interactive fuzzy satisfaction technique is used to optimize the opposing objective functions simultaneously. In [21] and [22], without considering uncertainties, a cuckoo search and a combined GA/PSO approach were proposed for optimal static DER planning to improve the voltage profile and reduce power loss, respectively. A dynamic multi-objective model for the EDNEP problem in the presence of DER is presented in [23]. Even though the proposed model simultaneously optimizes two objective functions namely, total costs and degree of satisfaction of the technical constraints using a hybrid multi-objective immune genetic algorithm, it is unable to analyze the reliability benefits of DER and their impacts on EDNEP decisions. More importantly, the uncertainty of the load is not taken into account. A multi-objective dynamic formulation based on the shuffled bat algorithm for the optimal allocation of DER considering power losses, cost and voltage deviation is introduced in [24]. Voltage-dependent load models are successfully taken into account, however, uncertainties and reliability impact of DER are neglected. In another study conducted in [25], a dynamic multi-objective mixed integer linear programming framework for the EDNEP problem is constructed which takes into account the reliability impact of DER. K-means clustering technique is used to represent the uncertainty and correlation in the load and DER production. In Ref. [26], without considering uncertainty and reliability impact of DER, an approximate nonlinear programming based model for the static allocation of DER is developed that aims to minimize a cost function. The objective of this study is to reduce the calculation time of a mathematical optimization technique while preserving the quality of solution. A hybrid fuzzy GA based model is proposed in [27] to find the location, type and size of DER to maximize customer benefit and reduce network losses. The problem of static sizing of DER in a hybrid power system with wind and energy storage units considering the reliability index as an optimization constraint, is investigated in [28]. Although uncertainties are included using the autoregressive moving average technique, historical data need to be collected first and analyzed to generate the required uncertainty model which increases the computational burden of the problem. The research work proposed in [29], provides a new solution for the problem of loss allocation in EEDNs considering the effects of various types of DER and voltage-dependent load models. DER are categorized based on their real and reactive power generation ability. Refs. [30-33], without considering uncertainty and networks reliability, have focused on the static modelling of DER siting and sizing in EEDNS and used meta-heuristic algorithms to solve the model. The objective functions including minimizing power losses, maximizing voltage stability index, and improving voltage profile are converted to one objective function using the weighting coefficients. Ref. [34], have considered simultaneous placement of DER and capacitor banks in view of harmonic pollution in EEDNS. Minimization of power losses and loadability maximization are selected as the objective functions for the optimal DER allocation in [35]. System loadability is defined as the capacity of the system with which the maximum load could be connected without violating the system and operating constraints. Ref. [36], introduces a new multiobjective multi-stage formulation for the EDNEP problem taking into account the reliability benefits of DER. However, it fails to address the uncertainties that the problem encounters. In [37], the optimal placement and scheduling of dispatchable DER for loss minimization is investigated. In Refs. [38] and [39] fuzzy numbers have been utilized to address the uncertainties in a static DER planning problem. Improved versions of harmony search algorithm are implemented in [40] and [41] for solving the static DER planning problem. The uncertainties are modelled using Monte Carlo method, but the network reliability is neglected. A dynamic model for DER planning is proposed in [42] with the aim of evaluating economic regulations on the EDNEP which takes into account load and DER uncertainties and network reliability indices. The impact of optimal placement of DER on the total harmonic distortion level of the EEDNS is investigated in [43]. Uncertainties and load growth are included in the proposed static model. Recently, an 
integrated EDNEP problem in the presence of DER considering the reliability of network and uncertainties is introduced in [44]. Scenario-based modeling is used to include uncertainties and GA is utilized as the optimization tool. Although it proposes a comprehensive planning model, it is a static planning model and also does not include the voltage-dependent load models in the formulation. In a similar study conducted in [45], a dynamic EDNEP problem is considered by including the load uncertainty via Monte Carlo simulation technique. The effects of the uncertainties on the optimal solution and network parameters are effectively discussed. However, the reliability evaluation of the network in the presence of DER is not investigated. To sum up the literature survey, Table 1 shows the outline review of the published papers in the DER planning problem. The papers are evaluated from different aspects and a complete comparison is carried out.

\subsection{Contributions}

Although the reviewed studies provide important insights into the DER planning problem, none of them have considered a stochastic dynamic planning framework incorporating the reliability benefits and voltage-dependent load models simultaneously. Therefore, to address the shortcomings of the reviewed studies, a stochastic dynamic reliability-based framework is proposed for the integration of DER into EEDNs in this paper. The proposed methodology is based on the DISCO's viewpoint and aims to maximize the DISCO's profit by increasing the income and reducing the costs. To cope with the load uncertainty, an RO approach is employed to model the uncertain parameters, and accordingly, the robust DER planning problem is solved. The solution of the proposed optimization model provides the size, location, and power factor of DER. Moreover, the best year of DER installation as well as the need for transformers and/or distribution lines upgrading are the other optimization variables determined by the proposed pseudo-dynamic approach. One of the other practical aspects of the proposed model is the consideration of the impact of the load using the practical voltage-dependent load models in power flow calculations, reliability evaluations, and energy selling to customers. Moreover, a new heuristic approach is proposed and applied for solving the formulated planning problem. This algorithm is obtained by a combination of harmony search algorithm (HSA) and firefly algorithm (FA). The proposed combined optimization algorithm outperforms the original algorithm in terms of solution quality, convergence characteristic and calculation time. The effectiveness of the proposed planning model has been demonstrated with the aid of a case study based on a typical EEDN. In short, regarding the analysed research works in the previous section and summarized in Table 1, the main contributions of this paper can be stated as follows:

- Different from most of the works listed in Table 1, which used the static planning approach, this paper formulates a dynamic DER planning approach to provide more accurate results.

- The proposed approach considers the impact of the practical voltage-dependent load models in power flow calculations, reliability evaluations, and energy selling to customers simultaneously. To the best of the authors' knowledge, none of the papers listed in Table 1 has included all these three aspects together in their formulations.

- The uncertainty of the load is considered and RO is utilized to cope with the uncertainty. It provides a computationally tractable formulation to make a tradeoff between the riskiest and/or the most conservative solution. Moreover, it does not require the probability distribution function of the load demand, unlike other stochastic methods.

- A new meta-heuristic optimization method based on the HSA algorithm is presented to solve the formulated dynamic model. The proposed new algorithm is faster and generates better solutions.

\subsection{Paper organization}

The rest of the paper is organized as follows. Deterministic mathematical formulation of the proposed DER planning is presented in Section 2. Section 3 describes the robust counterpart problem of the proposed model. The solution methodology of 
the proposed planning model by the new HSA approach is provided in Section 4. Numerical results are given in Section 5. Finally, the main conclusions are summarized in Section 6.

\section{Deterministic model description}

The decision variables of the proposed dynamic model are:

- Expansion the capacity of existing substations;

- Upgrading the existing feeders;

- $\quad$ Size, power factor, and location of DER;

- The best investment time for each facility within the planning horizon.

In the proposed EDNEP model, all of these decision variables are found by the proposed optimization algorithm (i.e., CHSFA) excluding the last one which is determined by the pseudo-dynamic strategy. In this section, the mathematical formulation of the proposed planning problem is introduced.

\subsection{Load models}

As discussed in [48], the voltage-dependent load models have an effect on the optimal DER planning in real-world problems. As a result, in order to obtain a proper scheme for DER installation in EEDNs, the impact of voltage-dependent load models are analyzed in this paper. Generally, there are three frequently used load models in EEDN studies: the industrial, commercial, and residential models. These load models can be mathematically represented as follow [48]:

$$
\begin{aligned}
& P_{i}^{D}=P_{0 i}^{D} \times V_{i}^{\alpha} \\
& Q_{i}^{D}=Q_{0 i}^{D} \times V_{i}^{\beta}
\end{aligned}
$$

Typical values of $\alpha$ and $\beta$ are given in [48]. By considering the annual load growth rate, the load at bus $i$ and in the year $t$ of the planning period can be modeled as below [6].

$$
\begin{aligned}
& P_{i \neq}^{D}=P_{0 i}^{D} \times V_{i}^{\alpha} \times(1+\tau)^{t-1} \\
& Q_{i \neq}^{D}=Q_{0 i}^{D} \times V_{i}^{\beta} \times(1+\tau)^{t-1}
\end{aligned}
$$

It is worth mentioning that only the peak load is considered in the load modelling in this paper because if the network equipment such as lines and transformers are designed and selected based on the peak loading condition, they can definitely work safely under normal operating conditions of the network. However, this assumption is not mandatory and the proposed planning model has the capability to include different loading levels over the planning horizon.

\subsection{Objective function}

The proposed model of this study is from the DISCO's perspective. Therefore, different from other studies in this area which mainly consider cost as the objective function, maximization of the DISCO's profit is considered as the most important objective in this paper. The reason is that it has been shown in [6] that in the presence of voltage-dependent loads, formulating objective function for the profit maximization is more profitable for the DISCO than the case with the objective function of cost minimization. It is also assumed that the DISCO is the owner of DER. Therefore, while the DISCO is responsible for EEDN maintenance and operating costs, it is also assumed to be accountable for the operation and maintenance costs of DER. Hence, the net profit of the DISCO in each year of the planning period is the objective function which should be maximized and defined by [6]: 
$\max$ Profit $=($ Income - Cost $)$

where Income and Cost have been defined in (6) and (7), respectively. The DISCO's income is from selling energy to customers and can be calculated as follows [6]:

$$
\text { Income }=8760 \times \sum_{i=1}^{N_{\text {th }}} \pi_{i}^{c} \times P_{i}^{D}
$$

Besides, the total DISCO's costs consist of three main components, namely the investment, operation, and maintenance cost [1]:

$$
\operatorname{Cost}=\operatorname{Inv} C+\mathrm{OprC}+\mathrm{RelC}
$$

The investment cost demonstrates the total annual costs of the new equipment that is needed to be added to the system, including the new transformers and DER, and also the expansion costs of the existing ones, which require reinforcement. The investment cost covers the feeders' upgrade cost as well. The second term in (7) represents the annual operating costs of the EEDN, which cover the cost of purchasing power from the grid along with the operation and predictive maintenance costs of DER. The third term represents the annual reliability cost calculated based on the total unsupplied load after an outage. Provided that the DER are allowed to operate in islanded mode [49], they can supply loads of the EEDN during both scheduled and unscheduled outage events, which can improve the network reliability. The total unsupplied load at each load point of the network depends on the topology of the network and location of the protection devices. In this paper, the proposed method of [50] is applied to evaluate the unserved energy of each load point. The mathematical description of each term of the DISCO's cost is as follows [51]:

$$
\begin{aligned}
& \operatorname{Inv} C=\left(\frac{d(1+d)^{n}}{(1+d)^{n}-1}\right)\left(\sum_{k=1}^{N_{s s}} \sum_{j=1}^{N_{T}} C_{k, j}^{T}+\sum_{u=1}^{N_{c g}} C_{l h v}^{D G} \times S_{u}^{D G}+\sum_{l=1}^{N_{m p}} C_{u p g}^{F} \times L_{l}\right) \\
& \operatorname{OprC}=8760 \times\left(\sum_{k=1}^{N_{s S}} \lambda_{k}^{g} \times P_{k}^{g r i d}+\sum_{u=1}^{N_{c g}} C_{O}^{D G} \times S_{u}^{D G} \times p f_{u}^{D G}\right) \\
& \operatorname{RelC}=\sum_{i=1}^{N_{\text {tu }}} C_{i}^{E N S} \times E N S_{i}
\end{aligned}
$$

It is worth mentioning that the following assumptions are considered in evaluating the unserved energy:

- For a successful islanding event, the output power of all DER within the island should be higher than or equal to a certain percentage of the load power. This percentage is assumed to be $100 \%$ in this paper.

- When an island is created, relying on renewable DER might bring about voltage and frequency stability problems. Hence, conventional DER are usually in charge of controlling the power balance within the island between generation and the load. In other words, to guarantee a successful islanding, a minimum percentage of conventional DER should be assumed and below this threshold, the island would not be successful. In [49], this threshold is assumed to be $60 \%$. In this paper, all DER are assumed to be conventional ones such as diesel or natural iii units, fuel cell and microturbines.

- The topology of the network and customers at load points do not change during the planning period.

- It is straightforward to include the salvage value of the newly added generations in (8). However, in this paper, this cost item has been neglected for the sake of simplicity. 


\subsection{Constraints}

The constraints regarding the proposed planning problem are described here.

1) Network power balance: This constraint is fulfilled by load flow calculations. In this paper, the forward-backward sweep method for radial EEDNs, which is reliable and easy to implement, is employed [52].

2) Voltage limit: Voltage magnitude at each bus should remain within the safe operating limits as:

$V_{\min } \leq V_{i} \leq V_{\max }, \forall \mathrm{i} \leq \mathrm{N}_{L B}$

3) Maximum capacity of the distribution feeders: The maximum transferable power capacity of the feeders has to be met over the planning period:

$S_{l} \leq S_{l}^{\max }, \forall \mathrm{l} \leq \mathrm{N}_{L}$

This constraint may be violated as the load of the system grows. In this case, the overloaded feeders must be upgraded. However, proper allocation of DER in an EEDN may relieve congestion on feeders and therefore mitigate or defer upgrade investment.

4) Maximum capacity and power factor limits of DER: The maximum possible installed capacity and power factor limits of DER should be enforced as follows:

$$
\begin{aligned}
& 0 \leq S_{u}^{D G} \leq S_{\max }^{D G} \\
& p f_{\min }^{D G} \leq p f_{u}^{D G} \leq p f_{\max }^{D G}
\end{aligned}
$$

5) Maximum DER penetration level: In order to avoid malfunction of protective devices due to the reverse power flow, the following inequality constraint must be fulfilled [49]:

$$
\sum_{u=1}^{N_{c a s}} S_{u}^{D G} \times p f_{u}^{D G} \leq 0.6 \times \sum_{k=1}^{N_{s s}} P_{k}^{\text {grid }}+0.3 \times \sum_{i=1}^{N_{\text {th }}} P_{i}^{D}
$$

6) Number of DER: In some EEDNs, there might be a limitation on the maximum number of DER installed in the system. Accordingly, the following constraint should be satisfied [49]:

$\sum_{u=1}^{N_{c h}} \operatorname{sign}\left(S_{u}^{D G}\right) \leq \mathrm{M}_{D G}$

where:

$\operatorname{sign}\left(S_{u}^{D G}\right)=\left\{\begin{array}{lll}1 & \text { if } & S_{u}^{D G}>0 \\ 0 & \text { if } & S_{u}^{D G} \leq 0\end{array}\right.$

It should be noted that constraints (13) and (14) are simply handled by forcing optimization variables, i.e, $S_{u}^{D G}$ and $p f_{u}^{D G}$ to be within their bounds during the optimization process. For constraints (11), (12), (15) and (16), the penalty function approach is used to transform the constrained problem into an unconstrained one $[53,54]$. In this approach, a simple way to penalize infeasible solutions is to apply a constant penalty, consists of a penalty parameter multiplied by a measure of violation of the constraints, to those solutions that violate feasibility in any way. Therefore, the penalized objective function consists of the original objective function in (5) plus a penalty term. 


\section{Robust model description}

In this section, the robust formulation of the proposed EDNEP model in the presence of DER is discussed. Among the vast amount of literature on the RO approach, a tractable RO modeling proposed in $[15,16]$ has been utilized. The main components in the RO modeling are the uncertainty sets and the robust counterpart problem. The uncertainty of the input data is introduced by the uncertainty sets, which include all, or most, possible values that may be realized for the uncertain parameters. Besides, a deterministic problem called the robust counterpart of the problem is associated with the uncertain problem. It is to be noted that, unlike the stochastic optimization method, the uncertainty model in an RO formulation is not a probability distribution, but rather a deterministic set. It is the choice of the decision maker to construct such an uncertainty set according to the historical data or estimate it with a confidence interval. The robust counterpart is obtained by replacing the random parameters with their potential values defined in the uncertainty sets in the deterministic formulation. This is an important characteristic of the RO technique, which makes it computationally tractable even for medium- or large-scale problems.

In this paper, the uncertain parameter is the load at each bus of the network. It is assumed that the load of each bus consists of a forecasted value plus an error component. The error component is defined as a deviation from the forecasted value. Thus, in each year of the planning period, the load at each bus of the network is as follows:

$$
P_{0 i, t}^{D}=\bar{P}_{0 i, t}^{D}+\varepsilon_{i,}^{D} z_{i \neq}^{D}
$$

where $z_{i, t}^{D} \in\{0,1\}$ is a binary variable used to determine which bus has the load uncertainty. $z_{i, t}^{D}=0$ indicates that bus $i$ at year $t$ does not have load uncertainty and $z_{i, t}^{D}=1$ means an uncertain load for bus $i$ at year $t$. Thus, the uncertainty set for the network loads in each year of the planning period becomes:

$$
\Pi^{t}=\left\{P_{0 t}^{D} \in \mathfrak{R}^{N_{t h}} \mid P_{0 i, t}^{D}=\bar{P}_{0 i, t}^{D}+\varepsilon_{i, t}^{D} z_{i, t}^{D}, \varepsilon_{i, t}^{D} \in\left[-\widehat{\varepsilon}_{i, t}^{D},+\widehat{\varepsilon}_{i, t}^{D}\right], z_{i, t}^{D} \in\{0,1\}, \forall i \in \Lambda_{L B}, \sum_{i=1}^{N_{t h}} z_{i, t}^{D} \leq \Gamma^{t}\right\}
$$

This set contains all the load of the network that faces uncertainty. In the above equation, parameter $\Gamma$, which is called the "budget of uncertainty", controls the number of buses in which the load value differs from the forecasted one. Indeed, $\Gamma$ adjusts the conservatism degree of the solution. This parameter takes integer values between 0 and $N_{L B}$ (the number of uncertain parameters). When $\Gamma=0$, it is equal to the deterministic condition, where there is no uncertainty about the load values. By increasing the $\Gamma$ parameter, the uncertainty set is enlarged. This means that the number of buses with load uncertainty increases, and as a result, the solution of the robust model is more conservative against a higher degree of uncertainty. Finally, when $\Gamma^{t}=N_{L B}$, the most conservative solution is achieved. The decision maker has the opportunity to make a tradeoff between the riskiest and/or the most conservative solution.

According to the above discussion, the robust counterpart of (5) can be written as follows:

$$
\begin{aligned}
& \min \left(\max _{P_{0}^{\circ} \in \Pi}\left(\frac{1}{1+\text { Profit }}\right)\right) \\
& \text { subject to : constraints }(11)-(16)
\end{aligned}
$$

As can be seen, the robust planning approach considers all possible values of the load in its corresponding uncertainty set and computes a worst-case optimal solution, which is protected against the change of uncertain parameters. Such a solution remains feasible, and therefore, robust for any realization of uncertain loads. In order to better illustrate the efficiency of the RO model, it should be compared with deterministic models and scenario-based techniques which are the most common methods to construct 
stochastic models. Deterministic models only consider the nominal realization of the uncertain parameters and therefore the feasibility of the solution is only guaranteed for one realization. Similarly, in the scenario-based models, only a finite set of the pre-selected scenarios for the uncertain parameters are considered and the feasibility of the solution is only guaranteed for those scenarios. Moreover, the probability distribution function of the uncertain parameter is not required to be determined for the RO approach, unlike with other stochastic models which totally depend on the probability distribution function of the uncertain parameter.

It should be noted that optimization variables of the robust model are the same as the deterministic model which include the size, location, power factor, and the best year of DER installation as well as the need for transformers and/or distribution lines investment.

\section{Proposed optimization methodology}

\subsection{The modified harmony search algorithm}

The HSA has been inspired by the improvisation process of composing a piece of music [55-57]. The main advantages of HSA are its simple concept and model, easy implementation, less adjustable parameters, and quick convergence. This algorithm has been previously applied to different power system planning and optimization problems, such as economic load dispatch problem [55], distribution system planning [40, 41], optimal capacitor placement [56] and optimal operation of storage devices [57]. The capability and performance of this algorithm have been compared with other methods and it has been shown that it performs well compared to various optimization algorithms.

In the first step of the HSA, the $H M$ is initialized by a $H M S \times N$ randomly generated matrix, in which $N$ is the number of optimization variables. The $H M$ resembles the initial population in the other evolutionary algorithms and each row of the $H M$ represents a solution vector of the optimization problem. After the $H M$ initialization, a new harmony vector is generated, which is called "improvisation". There are three rules used to generate this new harmony vector: $i$ ) HM consideration: Each component of the new harmony vector $\boldsymbol{x}^{\prime}=\left(x_{1}^{\prime}, x_{2}^{\prime}, \ldots, x_{N}^{\prime}\right)$ is randomly selected from the corresponding components stored in the HM with the probability of HMCR. ii) Pitch adjustment: Every component selected from the HM is further modified according to the $P A R$. The value of each component is changed during the pitch adjustment phase by $\mathrm{x}_{v}^{\prime} \pm \operatorname{rand}() \times B W$. iii) Random generation: Any component, which is not selected for memory consideration, will be randomly set to a value between the lower and upper bounds of its possible range with the probability of $(1-H M C R)$. The new improvised harmony vector is now assessed according to the value of the objective function. If the value of the objective function for the new harmony vector is better than that of the worst harmony in the $H M$, then the existing worst harmony is replaced with the new improvised harmony. This process is repeated until the maximum number of improvisations is obtained.

The HSA has many advantages, which have made it a reliable method for solving different optimization problems with higher complexity. Nevertheless, in order to improve the capability of the HSA for both local search and global exploration, a novel modification is proposed. The key idea in the proposed modification is based on forcing the population to move toward the best individual in order to decrease the possibility of trapping in local optima [58]. In this regard, a new scheme is proposed to perform the pitch adjustment phase of the HSA. Unlike the original HSA, in which each selected component for pitch adjustment is randomly changed in the range of $\pm B W$, in the new approach, the new harmony can mimic the best harmony vector stored in the HM. In the proposed combined harmony search and firefly algorithm (CHSFA), each selected component is altered by applying the procedure, which moves fireflies in the FA. The FA is another meta-heuristic optimization algorithm inspired by the 
movement of fireflies [59]. In the FA, each firefly is a solution of the optimization problem, and the brightness or light intensity value is assigned to each firefly. The brightness of each firefly is determined proportional to the value of the objective function to be optimized. In each iteration of the FA, fireflies move toward the brighter ones. Moreover, each firefly has a random movement. The proposed CHSFA has the same steps as the original HSA with the exception of the improvisation process, which is shown in Fig. 1. It can be observed that, in the CHSFA, each component selected for pitch adjustment phase experiences two movements: the first one is toward the best harmony vector in the $H M$ and the second one is a random movement. These two movements balance the exploration and exploitation abilities of the CHSFA and enhance its performance.

\subsection{Harmony vector codification}

In the proposed model, the size, power factor, and location of the DER are determined by the CHSFA. Thus, the harmony vector consists of two parts: The first part represents the installed capacity of the DER in each of the candidate buses and the second part is used for determining the power factor of the DER to be installed at the candidate busses. The dimension of each part of the harmony vector is equal to the number of candidate buses for the DER installation. Each element of the harmony vector is represented by an integer. Each integer number corresponds to a certain DER capacity or a certain power factor. In this method, the number zero means that no DER will be installed at the corresponding candidate bus. Given the capacity and power factor of DER, the power required to be supplied by the substation is calculated through the load flow calculations, which shows whether a new transformer needs to be installed in the substation or not. In addition, the number of feeders that need to be upgraded is determined.

\subsection{Harmony vector evaluation}

As shown in (20), the robust counterpart model of the proposed robust problem is in a min-max form. The proposed CHSFA is employed to solve this optimization problem. Each harmony vector stored in the HM or the new one generated in the improvisation process is considered as a possible solution to the problem. The procedure of evaluating each possible solution can be summarized as follows: first of all, the value of the budget of uncertainty, i.e. $\Gamma$, must be determined. Then, for each possible solution, $\Gamma^{t}$ load buses of the EEDN are randomly selected. For each selected bus, the load is randomly generated considering the uncertainty set defined in (19) and the load flow program runs. In the load flow program, a DER is regarded as a negative PQ bus with a constant power factor determined in the second part of the harmony vector. Using the load flow, the value of the objective function is calculated. Finally, after repeating this procedure for 1,000 randomly selected load buses, the worst value among the calculated objective functions (i.e. maximum value for profit) is chosen as the objective function for this solution. This number, i.e., 1000, is adequately large and it is usually used for the RO applications [16, 17]. In Fig. 2, the flowchart of exploiting the CHSFA for solving the robust DER planning problem is depicted.

\subsection{The dynamic planning strategy}

The proposed dynamic planning model is based on the pseudo-dynamic strategy [60]. This method consists of two phases. In the first phase, a static planning model is solved to obtain a solution that can meet the load requirements for the final year of the planning period in an optimal manner. In the second phase, the effect of load growth is explicitly considered and continuous concatenated single stage expansions of the distribution network are found. For each intermediate year between the first and the final year, an optimal intermediate system is determined. Each intermediate system uses only the set of equipment that has been determined from the first phase. After covering all intermediate years, each equipment from the first phase will have a time describing its expansion or construction year. The detailed steps of the proposed DER planning model considering the pseudodynamic method are as follow: 
Step 1: Determine the estimated load for the network buses for the final year of the planning horizon.

Step 2: Solve the problem for the last year using the proposed CHSFA considering all candidate buses as potential options for DER installation. All selected facilities from this step are considered as the candidates for the next steps.

Step 3: Select the first year of the planning period and specify the load growth for each load bus.

Step 4: Solve the problem using the CHSFA with the selected facilities in Step 2. The obtained result is the best solution for this year. All selected equipment for installation or expansion from this year is considered as existing ones for the next year.

Step 5: If the problem is solved for all intermediate years, stop. Otherwise, select the next intermediate year and, after determining the load growth for each load bus, go to Step 4.

It should be noted that the power factor of DER is fixed during the planning period. Thus, they must operate by the power factor, which is determined in Step 2 (i.e. solving the planning problem for the final year). In fact, the harmony vector structure does not constitute the second part for Steps 3-5.

\section{Simulation results}

The proposed EDNEP model is implemented to a medium voltage 38-bus EEDN [49]. This network includes a mix of residential, commercial, and industrial customers. The planning horizon for the network is five years. The total load in the beginning year of the planning period is 4.045 MW and 2.5 MVAR, which reaches 5.5032 MW and 3.4012 MVAR at the end of the planning period. This network is supplied from the grid by a substation with the capacity of $5 \mathrm{MVA}$ at the power factor of 0.85. Two three-phase 2-MVA transformers are available and can be installed to expand the substation. Buses 5, 33, 34, 35, 36, 37 and 38 are considered as candidates for DER installation [49]. The discrete size of DER is set from 100-2000 kVA with a 100-step interval between the sizes. In addition, the maximum number of DER in the network is limited to five [49]. These are set to operate at the practical power factors, which are $0.85,0.9,0.95$, and 1 . The technical and cost parameters of the network have been adopted from [3,6]. The fault rates and repair times of feeders have been considered $0.12 \mathrm{f} / \mathrm{km} . \mathrm{yr}$ and $3 \mathrm{~h}$, respectively. The other equipment of the network has been considered to be $100 \%$ reliable. The cost of the unsupplied energy for different types of customers has been adopted from $[3,6]$. The details of the input data and schematic diagram of the test network are given in Appendix A.

It is to be noted that the parameters of the original HAS and CHSFA are determined based on experience or by trial and error approach. In the numerical simulations of this paper, these parameters are set as follows: $H M S=15, P A R=0.6, H M C R=0.9, \beta 0=$ 1.2, $\gamma=($ iteration number/maximum number of iterations) and $\varphi=2.6$.

\subsection{The deterministic DER planning problem}

In the deterministic model, load uncertainty is not taken into account and the problem is solved by considering the objective function defined in (5) with constraints (11)-(16). First, in order to demonstrate the effectiveness of the proposed CHSFA, the deterministic model is solved separately by the original HSA and proposed CHSFA. For this purpose and due to the stochastic nature of these algorithms, both methods are run 20 times with different initial random values. Table 2 shows the best, average, and worst results for the net present value of the total profit of the planning period obtained by implementing the two methods. According to this table, the proposed CHSFA algorithm is superior and more efficient than the original HSA, since its best, average and worst profit out of 20 trials is more promising than those of the original HSA. A typical convergence curve of the two methods for the first year of planning with the same random initial values is compared in Fig. 3. It can be seen that the proposed optimization algorithm has better convergence capability than the original one, as it reaches a better objective function 
value in fewer iterations. This means that fewer iterations are required for the proposed algorithm, and therefore it is faster than the original one. Moreover, in order to compare the solution quality and robustness of the CHSFA with that of the HSA, deviation of the best and worst solutions from the corresponding average result are calculated by the following equations [53]:

$$
\begin{aligned}
& \text { Deviation of the best solution from the average result }(\%)=\frac{\mid \text { Best solution }- \text { Average result } \mid}{\text { Average result }} \times 100 \\
& \text { Deviation of the worst solution from the average result }(\%)=\frac{\mid \text { Worst solution }- \text { Average result } \mid}{\text { Average result }} \times 100
\end{aligned}
$$

Deviations of the best and the worst solutions of the proposed CHSFA and HSA from the corresponding average results (in terms of percentage) are tabulated in Table 3. According to this table, it can be observed that the solutions obtained by CHSFA have lower deviations from the average result. Also, the small value of deviation for both best and worst solutions confirms the algorithm's robustness in finding the global minima vicinity in any trial. Therefore, the outcomes of Tables 2 and 3 and Fig. 3 clearly show the efficiency, robustness, and stability of the results of the proposed CHSFA.

To further evaluate the robustness of the proposed CHSFA algorithm against the variation in parameters, a sensitivity analysis is done and results are shown in Table 4. In this table, the first column shows the initial value of each parameter. This value is perturbed in up and down directions while other parameters are constant, as indicated in the second column of the table. Also, the effect of simultaneous change of all the parameters is evaluated and shown in the last row of this table. For each parameter perturbation, best, average and worst profits out of 20 trials are reported. Moreover, the deviation from the solution with the initial parameters in terms of percentage is calculated and shown within each cell of the table. A positive sign for a deviation means profit with the perturbed parameter increases with respect to its initial solution (Table 3), therefore the solution with the perturbed parameter is better than the initial solution. For example, when $P A R-\triangle P A R=0.5$, the average profit becomes 4.6032, which is higher than the initial average profit of 4.5569 (Table 3) by $1.0160 \%$. The data of this table validates the robustness of the proposed optimization algorithm since only very small deviations are seen in the results of the sensitivity analysis.

The outcomes of solving the deterministic EDNEP problem by the proposed CHSFA are demonstrated in Table 5. The proposed dynamic model determines the optimal size of the DER that should be installed on each candidate bus at each year during the planning horizon. The required capacity is added to the previously installed DER until the target capacity which is determined in the first phase of pseudo-dynamic strategy, is reached by the end of planning period. According to this table, not all the candidate buses have been selected for DER installation and DER units are installed in only five buses of the network. Moreover, the size and power factors of DER are different for each bus and the size of DER increases as the load of the network grows. Interestingly, two buses which have not been nominated for DER installation, i.e., 5 and 35, are residential buses while other candidates are industrial or commercial ones. This is because the cost of energy not served for commercial and industrial loads is much higher than that for residential loads. Therefore, the optimization algorithm tends to install DER close to these type of loads so that the reliability cost of the network is minimized.

Table 6 shows the expansion costs over the planning horizon. Results of the network planning without considerations of DER are also given in this Table. In this case, the DISCO must upgrade network feeders and expand the existing substation, by installing new transformers in order to support the load growth. As observed in Table 6, the use of DER in the EDNEP makes a significant rise in the total profit of the planning period as a result of an increase in income and a decrease in total cost of the DISCO. The income of the DISCO increases because in the presence of DER the voltage profile of the network is improved, therefore the active and reactive load of the network increases due to the dependency of loads on the voltage. Hence, an opportunity is provided for the DISCO to sell more electricity to voltage-dependent loads. Although, when DER are installed, the 
cost related to the investment and operation of these resources is added to costs of the DISCO, other costs of the network such as reliability cost, upgrade cost and energy purchase cost from the grid drop remarkably.

The maximum reduction is in the cost of feeder upgrade, which is about $72.24 \%$. This saving is achieved by postponing most of the feeder's upgrades to the following years. For instance, in the case of network planning without considerations of DER, 4 , $8,5,2$, and 2 feeders must be upgraded in the first, second, third, fourth, and fifth years of the planning period, respectively. However, with the consideration of DER, only 4, 1, 2, 2, and 2 feeders should be upgraded over the planning period. In addition, the need for a new transformer installation is eliminated when DER are included in the planning. It is to be noted that the load flow calculations are used to determine the need for the line upgrade or substation expansion. In this regard, given the annual load growth rate, the capacity and power factor of DER, the load flow program runs and lines current and amount of power to be imported from the upstream grid is computed. If the power required to be supplied by the substation or current of any line is greater than its capacity, the upgrade is necessary. It is assumed in this paper that network upgrading does not cause any supply interruption for the network's customers.

The cost of purchasing power from the grid is diminished by $55.31 \%$, which represents a good result. The reliability evaluation is carried out for the test network before and after the installation of DER and accordingly the reliability cost is calculated. Reduction in the reliability costs for the whole planning horizon by employing DER is about $26.31 \%$ because DER are placed in commercial and industrial buses, which have a higher cost of ENS, and therefore they can supply loads during an outage event. A comparison between the unsupplied energy of the network in each year of the planning period for two different planning cases is presented in Fig. 4. As can be seen, as the load of the network grows over the years, the amount of unsupplied energy goes up accordingly for both cases. However, for the case of employing DER, the increase is smoother because the size of DER increases over the planning horizon as well with the load growth. This clearly demonstrates the benefit of the DER in improving the network's reliability.

. Utilization of DER in the EDNEP can also lessen the power losses with the EEDN. A comparison between the power losses in each year of the planning period for two different planning cases is made in Fig. 5. This shows another advantage of using DER in EEDN due to the fact that they are placed near the end of the feeders and reduce the current of all the upstream lines and hence decrease energy losses.

Another point from Table 5 and 6 is that the required investments in the network to meet the load at the end of the planning horizon do not need to be done in the beginning of the planning period. In other words, the best time for each construction and investment is considered as a decision variable in this paper. This is the advantage of the dynamic planning approach in which the investment cost is done yearly in a step-by-step manner as the load of the network grows, dissimilar to the static planning approach in which the whole investment needs to be done at the beginning of the project.

\subsection{The DER planning problem with load uncertainty}

The robust planning problem is composed of the objective function in (20) with constraints (11)-(16) and the uncertainty set defined in (19), which is solved by using the procedure described in Fig. 2. According to the defined uncertainty set, the budget of uncertainty $\Gamma$ which controls the number of buses in which the load value differs from the forecasted one takes values between 0 and the number of uncertain parameters (i.e. $N_{\mathrm{LB}}=37$ ). When $\Gamma=0$, it is equal to the deterministic condition, where there is no uncertainty about the load values. By increasing the $\Gamma$ parameter, the number of buses with load uncertainty increases, and as a result, the solution of the robust model is more conservative against a higher degree of uncertainty. Finally, when $\Gamma=37$, the most conservative solution is achieved. Moreover, the range of load variation is set to be $\widehat{\varepsilon}_{i, t}^{D}=0.1 \times \bar{P}_{0 i, t}^{D}$ for 
each load bus $i$ at year $t$, which means that $10 \%$ error is considered for the load forecasting.

Table 7 shows the results of solving the robust counterpart model for some values of $\Gamma$. The net present value of the total profit for various values of $\Gamma$ is displayed in Fig. 6. It can be concluded that the value of profit decreases when the uncertainty of load is taken into account in the EDNEP model. Moreover, as the $\Gamma$ gets larger, the net present value of the total profit increases. This is because the RO protects the system against the worst-case realization of the load; this worst-case is enlarged as $\Gamma$ grows. Hence, the model imports more power from the grid or expands the DER capacity. Consequently, as the $I$ rises, the cost of DISCO soars. The income of DISCO also increases as the $\Gamma^{\top}$ becomes larger. Therefore, as the $\Gamma^{t}$ becomes larger, the net present value of the total profit increases.

\section{Conclusions}

In this paper, a novel and practical approach for the dynamic planning of EEDNs is proposed in which the installation of DER is considered as an economic alternative for the DISCOs in order to respond to the load growth. The uncertainty of the network's load is considered in the proposed model and the robust optimization technique is used to address this uncertainty. Assuming that only the DISCO is authorized for DER integration, the objective function of the proposed model is to maximize the DISCO's profit. The reliability benefits of DER installation is also taken into consideration in the model. The developed planning model aims to find the best solution, which includes the DER size, location, and power factor. Besides, the best year for installation of DER is considered as another optimization variable to be determined by the pseudo-dynamic approach. Different types of load, such as industrial, residential, and commercial, are considered in load flow analysis, reliability evaluations and energy selling to customers. In addition, a new modified harmony search algorithm is presented for solving the formulated RO-based optimization model. Finally, the capability and performance of the proposed model have been demonstrated with the aid of a case study based on a typical EEDN. Main observations from the obtained results of this paper are:

- The proposed combined optimization algorithm, i.e., CHSFA outperforms the original HSA in terms of efficiency, robustness, and stability.

- All the potential benefits of DER integration for the DISCO can be achieved if an appropriate planning scheme is designed.

- The great advantage of DER integration is that the need for line upgrade or substation expansion due to load growth is mitigated or postponed to the later years, which brings about a significant decrease in the total cost, and therefore a significant increase in the total profit, over the planning period for the DISCO.

- Another benefit of utilization of DER is that it reduces power flow through the feeders and therefore lessens power losses. Also, it lowers the stress of the feeders and subsequently increases the duration of the lifetime of the equipment.

- DER also can supply loads of the EEDN during both scheduled and unscheduled outage events, which can improve the network reliability.

- The RO technique is a good method to handle load uncertainty in EDNEP as it provides the decision maker with a computationally tractable formulation to make a tradeoff between the riskiest and/or the most conservative solution. Moreover, it does not require the probability distribution function of the load demand, unlike other stochastic methods which require a probability distribution function of uncertain data discretized into a finite number of scenarios. Additionally, obtained results of the stochastic methods might not be reliable if an inaccurate distribution 
assumption is made.

- The tractability of RO is controlled by "budget of uncertainty", $\Gamma$ which adjusts the conservative degree of the solution. When $\Gamma^{\mathrm{t}}=0$, a deterministic problem is solved. By increasing the $\Gamma$ value, the uncertainty set enlarges, and as a result, the solution of the robust model is more conservative against a higher degree of uncertainty.

- The main challenge for RO approach is that it might lead to a large cost because the system behaviour is optimized against the worst-case realization of the random parameters. Therefore, the solution is often too conservative and pessimistic.

- The formulated planning model can be directly implemented in real life distribution networks which face load uncertainty and consist of a mixture of voltage-dependent loads, rather than constant loads.

Future research work will investigate the coordinated DER planning and network reconfiguration in an active EEDN while considering both conventional and renewable distributed energy resources. Moreover, private investors for DER should be considered, as their objectives are not aligned with the objectives of the DISCO.

\section{Acknowledgment}

The authors would like to sincerely thank the editor and 16 anonymous reviewers of this manuscript for providing us with insightful and constructive feedback and suggestions that significantly improved the quality and readability of the work. J.P.S. Catalão acknowledges the support by FEDER funds through COMPETE 2020 and by Portuguese funds through FCT, under SAICT-PAC/0004/2015 (POCI-01-0145-FEDER-016434), 02/SAICT/2017 (POCI-01-0145-FEDER-029803) and UID/EEA/50014/2013 (POCI-01-0145-FEDER-006961).

\section{References}

[1] V. Vahidinasab, "Optimal distributed energy resources planning in a competitive electricity market: Multiobjective optimization and probabilistic design," Renewable Energy, vol. 66, pp. 354-363, 2014.

[2] W. El-Khattam, Y. G. Hegazy, and M. M. A. Salama, "An Integrated Distributed Generation Optimization Model for Distribution System Planning," IEEE Trans. Power Syst., vol. 20, no. 2, pp. 1158-1165, May 2005.

[3] N. Khalesi, N. Rezaei, and M. R. Haghifam, "DG allocation with application of dynamic programming for loss reduction and reliability improvement," Int. J. Elect. Power Energy Syst. , vol. 33, no. 2, pp. 288-295, 2011.

[4] E. Naderi, H. Seifi, and M. S. Sepasian, "A Dynamic Approach for Distribution System Planning Considering Distributed Generation," IEEE Trans. Power Del., vol. 27, no. 3, pp. 1313-1322, Jul 2012.

[5] K. Qian, C. Zhou, M. Allan, and Y. Yuan, "Effect of load models on assessment of energy losses in distributed generation planning," Int. J. Elect. Power Energy Syst. , vol. 33 no. 6, pp. 1243-1250, 2011.

[6] R. Ebrahimi, M. Ehsan, and H. Nouri, "A profit-centric strategy for distributed generation planning considering time varying voltage dependent load demand," Int. J. Elect. Power Energy Syst. , vol. 44 no. 1, pp. 168-178, 2013.

[7] M.-R. Haghifam, H. Falaghi, and O. P. Malik, "Risk-based distributed generation placement," IET Gener. Transm. Distrib., vol. 2, no. 2, pp. 252-260, 2008.

[8] P. Dehghanian, S. H. Hosseini, M. Moeini-Aghtaie, and A. Arabali, "Optimal siting of DG units in power systems from a probabilistic multi-objective optimization perspective," Int. J. Elect. Power Energy Syst. , vol. 51, pp. 14-26, 2013. 
[9] C. L. T. Borges and V. F. Martins, "Multistage expansion planning for active distribution networks under demand and Distributed Generation uncertainties," Int. J. Elect. Power Energy Syst. , vol. 36, no. 1, pp. 107-116, 2012.

[10] A. Soroudi and M. Afrasiab, "Binary PSO-based dynamic multi-objective model for distributed generation planning under uncertainty," IET Renew. Power Gener., vol. 6, no. 2, pp. 67-78, 2012.

[11] F. Ugranlı and E. Karatepe, "Multiple-distributed generation planning under load uncertainty and different penetration levels," Int. J. Elect. Power Energy Syst. , vol. 46 pp. 132-144, 2013.

[12] V. A. Evangelopoulos and P. S. Georgilakis, "Optimal distributed generation placement under uncertainties based on point estimate method embedded genetic algorithm," IET Gener. Transm. Distrib., vol. 8, no. 3, pp. 389-400, 2014.

[13] A. Soroudi, R. Caire, N. Hadjsaid, and M. Ehsan, "Probabilistic dynamic multi-objective model for renewable and non-renewable distributed generation planning," IET Gener. Transm. Distrib., vol. 5, no. 11, pp. 1173-1182, 2011.

[14] D. Bertsimas and M. Sim, "The Price of Robustness," Operations Research, vol. 52, no. 1, pp. 35-53, 2004.

[15] D. Bertsimas and M. Sim, "Robust Discrete Optimization and Network Flows," Math. Programming, vol. 98, pp. 48-71, 2003.

[16] Dimitris Bertsimas, E. Litvinov, X. A. Sun, J. Zhao, and T. Zheng, "Adaptive Robust Optimization for the Security Constrained Unit Commitment Problem," IEEE Trans. Power Syst., vol. 28, no. 1, pp. 52-63, Feb 2013.

[17] I. Goroohi Sardou, M. Zare, and E. Azad-Farsani, "Robust energy management of a microgrid with photovoltaic inverters in VAR compensation mode," Int. J. Elect. Power Energy Syst., vol. 98, pp. 118-132, 2018.

[18] Y. Zhang, X. Han, M. Yang, B. Xu, Y. Zhao, and H. Zhai, "Adaptive robust unit commitment considering distributional uncertainty," Int. J. Elect. Power Energy Syst., vol. 104, pp. 635-644, 2019.

[19] F. S. Abu-Mouti and M. E. El-Hawary, "Optimal Distributed Generation Allocation and Sizing in Distribution Systems via Artificial Bee Colony Algorithm," IEEE Trans. Power Del., vol. 26, no. 4, pp. 2090-2101, Oct 2011.

[20] H. Doagou-Mojarrad, G. B. Gharehpetian, H. Rastegar, and J. Olamaei, "Optimal placement and sizing of DG (distributed generation) units in distribution networks by novel hybrid evolutionary algorithm," Energy, vol. 54, no. 1, pp. 129-138, 2013.

[21] Z. Moravej and A. Akhlaghi, "A novel approach based on cuckoo search for DG allocation in distribution network," Int. J. Elect. Power Energy Syst. , vol. 44 no. 1, pp. 672-679, 2013.

[22] M. H. Moradi and M. Abedini, "A combination of genetic algorithm and particle swarm optimization for optimal DG location and sizing in distribution systems," Int. J. Elect. Power Energy Syst. , vol. 34 no. 1, pp. 66-74, 2012.

[23] A. Soroudi and M. Ehsan, "A distribution network expansion planning model considering distributed generation options and techoeconomical issues," Energy, vol. 35, no. 8, pp. 3364-3374, 2010.

[24] C. Yammani, S. Maheswarapu, and S. K. Matam, "A Multi-objective Shuffled Bat algorithm for optimal placement and sizing of multi distributed generations with different load models," Int. J. Elect. Power Energy Syst., vol. 79, pp. 120-131, 2016.

[25] F. Ugranl1, "Analysis of renewable generation's integration using multi-objective fashion for multistage distribution network expansion planning," Int. J. Elect. Power Energy Syst., vol. 106, pp. 301-310, 2019.

[26] A. J. Gil Mena and J. A. Martín García, "An efficient approach for the siting and sizing problem of distributed generation," Int. J. Elect. Power Energy Syst., vol. 69, pp. 167-172, 2015.

[27] C. Nayanatara, J. Baskaran, and D. P. Kothari, "Hybrid optimization implemented for distributed generation parameters in a power system network," Int. J. Elect. Power Energy Syst., vol. 78, pp. 690-699, 2016. 
[28] A. M. Abd-el-Motaleb and S. K. Bekdach, "Optimal sizing of distributed generation considering uncertainties in a hybrid power system," Int. J. Elect. Power Energy Syst., vol. 82, pp. 179-188, 2016.

[29] K. M. Jagtap and D. K. Khatod, "Loss allocation in radial distribution networks with various distributed generation and load models," Int. J. Elect. Power Energy Syst., vol. 75, pp. 173-186, 2016.

[30] E. S. Ali, S. M. Abd Elazim, and A. Y. Abdelaziz, "Ant Lion Optimization Algorithm for Renewable Distributed Generations," Energy, vol. 116, pp. 445-458, 2016/12/01/ 2016.

[31] A. S. Bouhouras, K. I. Sgouras, P. A. Gkaidatzis, and D. P. Labridis, "Optimal active and reactive nodal power requirements towards loss minimization under reverse power flow constraint defining DG type," Int. J. Elect. Power Energy Syst., vol. 78, pp. 445-454, 2016.

[32] M. H. Moradi and M. Abedini, "A novel method for optimal DG units capacity and location in Microgrids," Int. J. Elect. Power Energy Syst., vol. 75, pp. 236-244, 2016.

[33] U. Sultana, A. B. Khairuddin, A. S. Mokhtar, N. Zareen, and B. Sultana, "Grey wolf optimizer based placement and sizing of multiple distributed generation in the distribution system," Energy, vol. 111, pp. 525-536, 2016/09/15/2016.

[34] N. Ghaffarzadeh and H. Sadeghi, "A new efficient BBO based method for simultaneous placement of inverter-based DG units and capacitors considering harmonic limits," Int. J. Elect. Power Energy Syst., vol. 80, pp. 37-45, 2016.

[35] M. M. Aman, G. B. Jasmon, A. H. A. Bakar, and H. Mokhlis, "A new approach for optimum simultaneous multi-DG distributed generation Units placement and sizing based on maximization of system loadability using HPSO (hybrid particle swarm optimization) algorithm," Energy, vol. 66, pp. 202-215, 2014.

[36] J. Aghaei, K. M. Muttaqi, A. Azizivahed, and M. Gitizadeh, "Distribution expansion planning considering reliability and security of energy using modified PSO (Particle Swarm Optimization) algorithm," Energy, vol. 65, pp. 398-411, 2014.

[37] A. Rahiminejad, B. Vahidi, M. A. Hejazi, and S. Shahrooyan, "Optimal scheduling of dispatchable distributed generation in smart environment with the aim of energy loss minimization," Energy, vol. 116, pp. 190-201, 2016.

[38] A. Zangeneh, S. Jadid, and A. Rahimi-Kian, "A fuzzy environmental-technical-economic model for distributed generation planning," Energy, vol. 36, no. 5, pp. 3437-3445, 2011.

[39] S. Ganguly and D. Samajpati, "Distributed Generation Allocation on Radial Distribution Networks Under Uncertainties of Load and Generation Using Genetic Algorithm," IEEE Transactions on Sustainable Energy, vol. 6, no. 3, pp. 688-697, 2015.

[40] K. S and V. K. D.M, "Optimal planning of active distribution networks with hybrid distributed energy resources using grid-based multi-objective harmony search algorithm," Applied Soft Computing, vol. 67, pp. 387-398, 2018.

[41] A. Rastgou, J. Moshtagh, and S. Bahramara, "Improved harmony search algorithm for electrical distribution network expansion planning in the presence of distributed generators," Energy, vol. 151, pp. 178-202, 2018.

[42] Y. Huang and L. Söder, "Evaluation of economic regulation in distribution systems with distributed generation," Energy, vol. 126, pp. 192-201, 2017.

[43] H. HassanzadehFard and A. Jalilian, "Optimal sizing and location of renewable energy based DG units in distribution systems considering load growth," Int. J. Elect. Power Energy Syst., vol. 101, pp. 356-370, 2018.

[44] A. Bagheri, H. Monsef, and H. Lesani, "Integrated distribution network expansion planning incorporating distributed generation considering uncertainties, reliability, and operational conditions," Int. J. Elect. Power Energy Syst., vol. 73, pp. 56-70, 2015.

[45] R. Hemmati, R.-A. Hooshmand, and N. Taheri, "Distribution network expansion planning and DG placement in the presence of uncertainties," Int. J. Elect. Power Energy Syst., vol. 73, pp. 665-673, 2015. 
[46] A. Zangeneh, S. Jadid, and A. Rahimi-Kian, "Promotion strategy of clean technologies in distributed generation expansion planning," Renewable Energy, vol. 34, no. 12, pp. 2765-2773, 2009.

[47] I. Ziari, G. Ledwich, A. Ghosh, and G. Platt, "Integrated Distribution Systems Planning to Improve Reliability Under Load Growth," IEEE Trans. Power Del., vol. 27, no. 2, pp. 757-765, Apr 2012.

[48] D. Singh, D. Singh, and K. S. Verma, "Multiobjective Optimization for DG Planning With Load Models," IEEE Trans. Power Syst., vol. 24, no. 1, pp. 427-436, Feb 2009.

[49] M. F. Shaaban, Y. M. Atwa, and E. F. El-Saadany, "DG Allocation for Benefit Maximization in Distribution Networks," IEEE Trans. Power Syst., vol. 28, no. 2, pp. 639 - 649, May 2013.

[50] I.-S. Bae and J.-O. Kim, "Reliability Evaluation of Distributed Generation Based on Operation Mode," IEEE Trans. Power Syst., vol. 22, no. 2, pp. 785-790, May 2007.

[51] H. Falaghi, C. Singh, M.-R. Haghifam, and M. Ramezani, "DG integrated multistage distribution system expansion planning," Int. J. Elect. Power Energy Syst. , vol. 33 no. 3, pp. 1489-1497, 2011.

[52] W. H. Kersting, Distribution system modeling and analysis. New York: CRC Press LLC, 2002.

[53] B. Jeddi, A. H. Einaddin, and R. Kazemzadeh, "A novel multi-objective approach based on improved electromagnetism-like algorithm to solve optimal power flow problem considering the detailed model of thermal generators," International Transactions on Electrical Energy Systems, vol. 27, no. 4, pp. e2293-n/a, 2017, Art. no. e2293.

[54] B. Jeddi, A. H. Einaddin, and R. Kazemzadeh, "Optimal power flow problem considering the cost, loss, and emission by multiobjective electromagnetism-like algorithm," 6th Conference on Thermal Power Plants (CTPP), 2016, pp. 38-45.

[55] B. Jeddi and V. Vahidinasab, "A modified harmony search method for environmental/economic load dispatch of real-world power systems," Energy Conv. Manage., vol. 78 pp. 661-675, 2014.

[56] E. S. Ali, S. M. Abd Elazim, and A. Y. Abdelaziz, "Improved Harmony Algorithm and Power Loss Index for optimal locations and sizing of capacitors in radial distribution systems," Int. J. Elect. Power Energy Syst., vol. 80, pp. 252-263, 2016.

[57] B. Jeddi and V. Vahidinasab, "Optimal operation strategy of distributed generators in a microgrid including energy storage devices," Smart Grid Conference (SGC), 2013, 2013, pp. 41-46.

[58] M. G. H. Omran and M. Mahdavi, "Global-best harmony search," Appl. Math. Comput., vol. 198 pp. 643-656, 2008.

[59] X.-S. Yang, "Firefly Algorithms for Multimodal Optimization," Stochastic Algorithms: Foundations and Applications, SAGA 2009, Lecture Notes in Computer Sciences, vol. 5792, pp. 169-178, 2009.

[60] I. J. Ramirez-Rosado and T. Giinen, "Pseudo-dynamic planning for expansion of power distribution systems," IEEE Trans. Power Syst., vol. 6, no. 1, pp. 245-254, Feb 1991. 
Table 1. Outline study of researches in DER planning problem

\begin{tabular}{|c|c|c|c|c|c|c|c|}
\hline Reference & Decision variables & Static/Dynamic & $\begin{array}{l}\text { Uncertainty } \\
\text { handling }\end{array}$ & $\begin{array}{c}\text { Voltage } \\
\text { dependent } \\
\text { load model }\end{array}$ & $\begin{array}{c}\text { Reliability } \\
\text { benefit of DER }\end{array}$ & Objective function(s) & $\begin{array}{l}\text { Optimization } \\
\text { method }\end{array}$ \\
\hline [1] & site + size + type & S & $\checkmark$ & & & Min cost, Min emission & $\begin{array}{l}\text { E-constraint } \\
\text { technique }\end{array}$ \\
\hline [2] & site + size & $\mathrm{S}$ & & & & Min cost & $\begin{array}{l}\text { Classical } \\
\text { MINLP }\end{array}$ \\
\hline [3] & site + size & $\mathrm{S}$ & & & $\checkmark$ & Max (benefit-cost) & DP \\
\hline [4] & site + size & $\mathrm{D}$ & & & & Min cost & GA-OPF \\
\hline [6] & site + size + power factor & $\mathrm{S}$ & & $\checkmark$ & & Max DISCOs profit & GA \\
\hline [7] & site + size & $\mathrm{S}$ & $\checkmark$ & & & Min cost, Min risk & NSGA-II \\
\hline [8] & site & $\mathrm{S}$ & $\checkmark$ & & $\checkmark$ & $\begin{array}{l}\text { Min cost, Min loss, } \\
\text { Min outage cost }\end{array}$ & NSGA-II \\
\hline [9] & site + size & $\mathrm{D}$ & 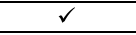 & & $\checkmark$ & Min cost & GA \\
\hline$[10]$ & site + size + type & $\mathrm{D}$ & $\frac{1}{2}$ & & & Min cost, Min emission & Binary PSO \\
\hline [11] & site + size & $\mathrm{S}$ & $\checkmark$ & & & Min loss & ANN \\
\hline [12] & site + size + type & $\mathrm{S}$ & $\checkmark$ & & & Min cost & GA \\
\hline$[13]$ & site + size + type & $\mathrm{D}$ & $\checkmark$ & & & $\begin{array}{l}\text { Min cost, } \\
\text { Min technical risk }\end{array}$ & NSGA-II \\
\hline$[19]$ & site + size + power factor & $\mathrm{S}$ & & & & Min power loss & $\mathrm{ABC}$ \\
\hline$[20]$ & site + size + type & S & & & & $\begin{array}{c}\text { Min power loss, } \\
\text { Min cost, Min emission }\end{array}$ & $\begin{array}{l}\text { Hybrid MO } \\
\text { MSFLA-DE }\end{array}$ \\
\hline [21] & site + size & $\mathrm{s}$ & & & & $\begin{array}{c}\text { Max voltage profile, } \\
\text { Min loss }\end{array}$ & $\mathrm{CS}$ \\
\hline [22] & site + size & $\mathrm{s}$ & & & & $\begin{array}{c}\text { Min loss, Max voltage profile, } \\
\text { Min voltage stability }\end{array}$ & $\begin{array}{l}\text { Combined } \\
\text { GA/PSO }\end{array}$ \\
\hline [23] & site + size & D & & & & $\begin{array}{l}\text { Min cost, Min technical } \\
\text { dissatisfaction }\end{array}$ & $\begin{array}{c}\text { Hybrid } \\
\text { Immune GA }\end{array}$ \\
\hline [24] & site + size & $\mathrm{s}$ & & $\checkmark$ & & $\begin{array}{c}\text { Min power loss, } \\
\text { Max voltage profile, } \\
\text { Min cost }\end{array}$ & MO SB \\
\hline [25] & site + size & $\mathrm{D}$ & $\checkmark$ & & $\checkmark$ & Min cost, Max DER utilization & MO MILP \\
\hline [26] & site + size & $\mathrm{S}$ & & & & Min cost, Min power loss & MINLP \\
\hline$[27]$ & site + size + type & $\mathrm{S}$ & & & & Min cost, Min power loss & Fuzzy GA \\
\hline [28] & size + type & $\mathrm{S}$ & $\checkmark$ & & $\checkmark$ & Min cost & SAEA \\
\hline [29] & type & $\mathrm{S}$ & & $\checkmark$ & & Min loss & $\begin{array}{c}\text { Mathematical } \\
\text { method }\end{array}$ \\
\hline$[30]$ & site + size & $\mathrm{s}$ & & & & $\begin{array}{c}\text { Min power loss, } \\
\text { Max voltage profile, Min } \\
\text { voltage stability index }\end{array}$ & ALOA \\
\hline [31] & number + site + size + type & $\mathrm{S}$ & & & & Min loss & Local PSO \\
\hline [32] & site + size & $\mathrm{s}$ & & & & $\begin{array}{c}\text { Min power loss, } \\
\text { Max voltage profile, Min } \\
\text { voltage stability index }\end{array}$ & $\begin{array}{c}\text { combined GA } \\
\text { and IWD }\end{array}$ \\
\hline [33] & site + size & $\mathrm{S}$ & & & $\checkmark$ & $\begin{array}{l}\text { Min reactive loss, Min voltage } \\
\text { deviation }\end{array}$ & GWO \\
\hline [34] & site + size & $\mathrm{S}$ & & & & $\begin{array}{l}\text { Min cost, Min power loss, } \\
\text { Max voltage profile }\end{array}$ & BBO \\
\hline [35] & site + size + type & $\mathrm{S}$ & & & & Max loadability & Hybrid PSO \\
\hline [36] & site + size & $\mathrm{S}$ & & & $\checkmark$ & $\begin{array}{l}\text { Min cost, Min energy not- } \\
\text { distributed, Min loss, Min } \\
\text { voltage stability index } \\
\end{array}$ & MO PSO \\
\hline [37] & site & $\mathrm{S}$ & & & & Min loss & TLBO \\
\hline [38] & site + size + type & $\mathrm{S}$ & $\checkmark$ & & & $\begin{array}{l}\text { Optimizing economic function, } \\
\text { technical function, and } \\
\text { environmental function } \\
\end{array}$ & NSGA-II \\
\hline [39] & site + size & $\mathrm{S}$ & $\checkmark$ & & & $\begin{array}{l}\text { Min power loss, } \\
\text { Max voltage index }\end{array}$ & GA \\
\hline [40] & site + size + power factor & $\mathrm{S}$ & $\checkmark$ & & & $\begin{array}{c}\text { Min power loss, } \\
\text { Max voltage profile, } \\
\text { Min cost } \\
\end{array}$ & $\begin{array}{l}\text { Grid-based } \\
\text { MO HSA }\end{array}$ \\
\hline [41] & site + size + type & $\mathrm{D}$ & $\checkmark$ & & & Min cost, Min emission & Improved HSA \\
\hline [42] & site + size & $\mathrm{D}$ & $\checkmark$ & & $\checkmark$ & Min cost & MILP \\
\hline [43] & site + size & $\mathrm{S}$ & $\checkmark$ & & & $\begin{array}{l}\text { Min Total Harmonic } \\
\text { Distortion, Min cost, } \\
\text { Min loss, Min emission }\end{array}$ & PSO \\
\hline [44] & site + size + type & $\mathrm{S}$ & $\checkmark$ & & $\checkmark$ & Min cost & GA \\
\hline [45] & site + size & $\mathrm{D}$ & $\checkmark$ & & & Min cost & PSO \\
\hline [46] & site + size + type & $\mathrm{S}$ & $\checkmark$ & & & $\begin{array}{l}\text { Min cost, Min emission, } \\
\text { Min loss }\end{array}$ & NSGA-II \\
\hline [47] & site + size & $\mathrm{D}$ & & & $\checkmark$ & Min cost & Discrete PSO \\
\hline [48] & site + size & $\mathrm{S}$ & & $\checkmark$ & & $\begin{array}{l}\text { Min power loss, } \\
\text { Min line power flow, } \\
\text { Max voltage index }\end{array}$ & GA \\
\hline Proposed & site + size + power factor & $\mathbf{D}$ & $\sqrt{2}$ & $\sqrt{2}$ & $\sqrt{2}$ & Max DISCOs profit & CHSFA \\
\hline \multicolumn{8}{|c|}{$\begin{array}{l}\mathrm{MO}=\text { multi-objective, } \mathrm{MINLP}=\text { mixed integer nonlinear programming, } \mathrm{ANN}=\text { artificial neural network, } \mathrm{DP}=\text { dynamic programming, } \mathrm{GA}=\text { genetic algorithm, } \mathrm{PSO}= \\
\text { particle swarm optimization, } \mathrm{OPF}=\text { optimal power flow, } \mathrm{ABC}=\text { artificial bee colony, } \mathrm{DE}=\text { differential evolution, } \mathrm{MSFLA}=\text { modified shuffled frog leaping algorithm, } \\
\mathrm{NSGA}=\text { non-dominated sorting genetic algorithm, } \mathrm{GWO}=\text { grey wolf optimizer, } \mathrm{ALOA}=\text { Ant Lion Optimization Algorithm, } \mathrm{CS}=\text { cuckoo search, } \mathrm{BBO}=\text { biogeography- } \\
\text { based optimization, } \mathrm{IWD}=\text { Intelligent Water Drops, } \mathrm{SB}=\text { Shuffled Bat, } \mathrm{SAEA}=\text { self-adapted evolutionary strategy, TLBO = teaching learning based optimization }\end{array}$} \\
\hline
\end{tabular}


Table 2. Net present value of total profit by two optimization algorithms

\begin{tabular}{cccc}
\hline Optimization Algorithm & Best Profit (M\$) & Average Profit (M\$) & Worst Profit (M\$) \\
\hline CHSFA & 4.6848 & 4.5569 & 4.4499 \\
HSA & 4.6335 & 4.4808 & 4.2972 \\
\hline
\end{tabular}

Table 3. Deviation of the best and the worst solutions of two algorithms from the corresponding average results

\begin{tabular}{ccc}
\hline Optimization algorithm & $\begin{array}{c}\text { Deviation of the best solution } \\
\text { from the average result (\%) }\end{array}$ & $\begin{array}{c}\text { Deviation of the worst solution } \\
\text { from the average result (\%) }\end{array}$ \\
\hline CHSFA & 2.8067 & 2.3480 \\
HSA & 3.4078 & 4.0974 \\
\hline
\end{tabular}

Table 4. Results of the sensitivity analysis for the proposed CHSFA

\begin{tabular}{ccccc}
\hline & Parameter & $\begin{array}{c}\text { Best profit } \\
(\text { Deviation \%) }\end{array}$ & $\begin{array}{c}\text { Average profit } \\
\text { (Deviation \%) }\end{array}$ & $\begin{array}{c}\text { Worst profit } \\
\text { Deviation \%) }\end{array}$ \\
\hline \multirow{2}{*}{$\mathrm{HMS}=15$} & $\mathrm{HMS}-\Delta \mathrm{HMS}=10$ & $4.6791(-0.1216)$ & $4.5217(-0.7724)$ & $4.4331(-0.3775)$ \\
& $\mathrm{HMS}+\Delta \mathrm{HMS}=20$ & $4.6841(-0.0149)$ & $4.5477(-0.2018)$ & $4.4309(-0.4269)$ \\
\hline \multirow{2}{*}{$\mathrm{PAR}=0.6$} & $\mathrm{PAR}-\Delta \mathrm{PAR}=0.5$ & $4.6795(-0.1131)$ & $4.6032(1.0160)$ & $4.4103(-0.8899)$ \\
& $\mathrm{PAR}+\Delta \mathrm{PAR}=0.7$ & $4.6712(-0.2903)$ & $4.5135(-0.9522)$ & $4.3102(-3.1393)$ \\
\hline \multirow{2}{*}{$\mathrm{HMCR}=0.9$} & $\mathrm{HMCR}-\Delta \mathrm{HMCR}=0.85$ & $4.6704(-0.3073)$ & $4.6026(1.0028)$ & $4.4181(-0.7146)$ \\
& $\mathrm{HMCR}+\Delta \mathrm{HMCR}=0.95$ & $4.6394(-0.9690)$ & $4.5137(-0.9480)$ & $4.4254(-0.5505)$ \\
\hline \multirow{2}{*}{$\beta_{0}=1.2$} & $\beta_{0}-\Delta \beta_{0}=0.7$ & $4.6812(-0.0768)$ & $4.4786(-1.7182)$ & $4.3469(-2.3146)$ \\
& $\beta 0+\Delta \beta_{0}=1.7$ & $4.6743(-0.2241)$ & $4.4120(-3.1797)$ & $4.3277(-2.7461)$ \\
\hline \multirow{2}{*}{$\varphi=2.6$} & $\varphi-\Delta \varphi=2$ & $4.6712(-0.9306)$ & $4.5872(0.6649)$ & $4.4501(0.0044)$ \\
& $\varphi+\Delta \varphi=3.2$ & $4.6787(-0.1302)$ & $4.5378(-0.4191)$ & $4.2211(-5.1416)$ \\
\hline \multirow{2}{*}{$\mathrm{All}$} & $\mathrm{Down}$ & $4.6732(-0.2476)$ & $4.5032(-1.1784)$ & $4.4217(-0.6337)$ \\
& $\mathrm{Up}$ & $4.6344(-1.0758)$ & $4.5001(-1.2464)$ & $4.2893(-3.7304)$
\end{tabular}


Table 5. Optimal DER installation capacities (MVA) over the planning period

\begin{tabular}{cccccccc}
\hline & \multicolumn{7}{c}{ Candidate buses for DER installation } \\
\cline { 2 - 8 } & Bus & Bus & Bus & Bus & Bus & Bus & Bus \\
& 5 & 33 & 34 & 35 & 36 & 37 & 38 \\
\hline $1^{\text {st }}$ year & 0 & 1.1 & 0.3 & 0 & 0.5 & 0.4 & 0.1 \\
$2^{\text {nd }}$ year & 0 & 1.2 & 0.3 & 0 & 0.5 & 0.5 & 0.1 \\
$3^{\text {rd }}$ year & 0 & 1.3 & 0.4 & 0 & 0.5 & 0.5 & 0.1 \\
$4^{\text {th }}$ year & 0 & 1.4 & 0.5 & 0 & 0.5 & 0.5 & 0.1 \\
$5^{\text {th }}$ year & 0 & 1.6 & 0.5 & 0 & 0.6 & 0.5 & 0.1 \\
$p_{\text {p. } .^{*}}$ & - & 0.9 & 0.95 & - & 0.95 & 0.95 & 0.95 \\
\hline
\end{tabular}

* Power factor

Table 6. Detailed results of two planning case studies

\begin{tabular}{|c|c|c|c|c|c|c|c|c|c|c|}
\hline \multirow{2}{*}{ Cost/Profit (M\$) } & \multicolumn{5}{|c|}{ Without DER } & \multicolumn{5}{|c|}{ With DER } \\
\hline & $1^{\text {st }}$ year & $2^{\text {nd }}$ year & $3^{\text {rd }}$ year & $4^{\text {th }}$ year & $5^{\text {th }}$ year & $1^{\text {st }}$ year & $2^{\text {nd }}$ year & $3^{\text {rd }}$ year & $4^{\text {th }}$ year & $5^{\text {th }}$ yea \\
\hline Annual profit & 0.4558 & 0.3465 & 0.3655 & 0.6666 & 0.7180 & 0.9601 & 1.3046 & 1.3864 & 1.4933 & 1.6123 \\
\hline Annual income & 3.4000 & 3.6549 & 3.9276 & 4.2190 & 4.5302 & 3.5471 & 3.8275 & 4.1255 & 4.4449 & 4.7979 \\
\hline Purchasing power & 2.4588 & 2.6533 & 2.8631 & 3.0892 & 3.3328 & 1.1003 & 1.1841 & 1.2806 & 1.3932 & 1.4746 \\
\hline Transformer cost & - & 0.0064 & - & - & - & - & - & - & - & - \\
\hline DER investment & - & - & - & - & - & 0.1545 & 0.0129 & 0.0129 & 0.0129 & 0.0193 \\
\hline Feeder upgrading & 0.1607 & 0.2980 & 0.3203 & 0.0542 & 0.0367 & 0.1199 & 0.0135 & 0.0317 & 0.0284 & 0.0301 \\
\hline Reliability cost & 0.3247 & 0.3507 & 0.3787 & 0.4090 & 0.4418 & 0.2378 & 0.2568 & 0.2774 & 0.2996 & 0.3235 \\
\hline $\mathrm{NPV}^{*}$ of total & 1.7500 & & & & & 4.6848 & & & & \\
\hline
\end{tabular}

Table 7. Obtained results from the robust counterpart of the RO model for different values of $\Gamma$

\begin{tabular}{|c|c|c|c|c|c|c|c|c|c|c|c|c|c|c|}
\hline & & & \multicolumn{6}{|c|}{$\Gamma=14$} & \multicolumn{6}{|c|}{$\Gamma=25$} \\
\hline & & & $1^{\text {st } y r}$ & $2^{\text {nd }} \mathrm{yr}$ & $3^{\text {rd } y r}$ & $4^{\text {th }} \mathrm{yr}$ & $5^{\text {th } y r}$ & $p . f$ & $1^{\mathrm{st} y r}$ & $2^{\text {nd } y r}$ & $3^{\text {rd } y r}$ & $4^{\text {th }} \mathrm{yr}$ & $5^{\text {th }} \mathrm{yr}$ & $\overline{p . f}$ \\
\hline \multirow{7}{*}{ 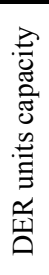 } & \multirow{7}{*}{ 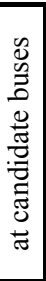 } & Bus 5 & 0 & 0 & 0 & 0 & 0 & - & 0 & 0 & 0 & 0 & 0 & - \\
\hline & & Bus 33 & 0.8 & 0.8 & 0.8 & 0.8 & 0.9 & 0.9 & 0.1 & 0.1 & 0.4 & 0.6 & 0.9 & 0.95 \\
\hline & & Bus 34 & 0 & 0 & 0 & 0 & 0 & - & 0.4 & 0.4 & 0.4 & 0.4 & 0.4 & 0.95 \\
\hline & & Bus 35 & 0.6 & 0.8 & 0.9 & 0.9 & 0.9 & 0.95 & 0.3 & 0.4 & 0.4 & 0.4 & 0.4 & 0.85 \\
\hline & & Bus 36 & 0.5 & 0.5 & 0.6 & 0.8 & 0.9 & 0.95 & 1.4 & 1.4 & 1.4 & 1.4 & 1.4 & 0.95 \\
\hline & & Bus 37 & 0.4 & 0.4 & 0.4 & 0.4 & 0.4 & 0.95 & 0.2 & 0.2 & 0.3 & 0.3 & 0.3 & 0.9 \\
\hline & & Bus 38 & 0.1 & 0.1 & 0.1 & 0.1 & 0.1 & 0.95 & 0 & 0 & 0 & 0 & 0 & - \\
\hline \multirow{4}{*}{ 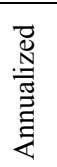 } & \multirow{4}{*}{ 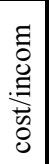 } & Income & 3.5640 & 3.8344 & 4.1355 & 4.4226 & 4.7033 & & 3.6217 & 3.8941 & 4.2533 & 4.5659 & 4.9718 & \\
\hline & & Cost & 2.6110 & 2.5960 & 2.8123 & 2.9757 & 3.1543 & & 2.6535 & 2.6683 & 2.9557 & 3.0796 & 3.3555 & \\
\hline & & Profit & 0.9530 & 1.2384 & 1.3232 & 1.4469 & 1.5490 & & 0.9682 & 1.2258 & 1.2976 & 1.4863 & 1.6163 & \\
\hline & & NPV & 4.5178 & & & & & & 4.5653 & & & & & \\
\hline
\end{tabular}




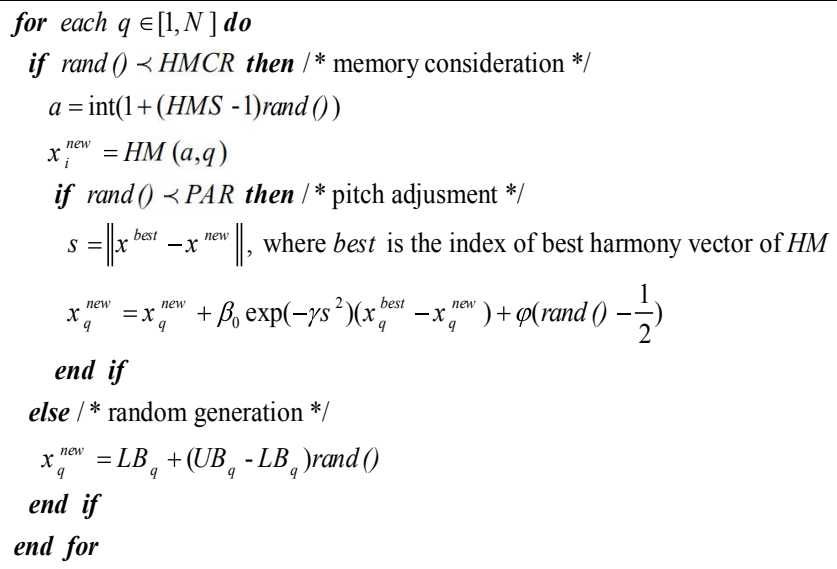

Fig. 1. Pseudo code of improvisation process in the proposed CHSFA 


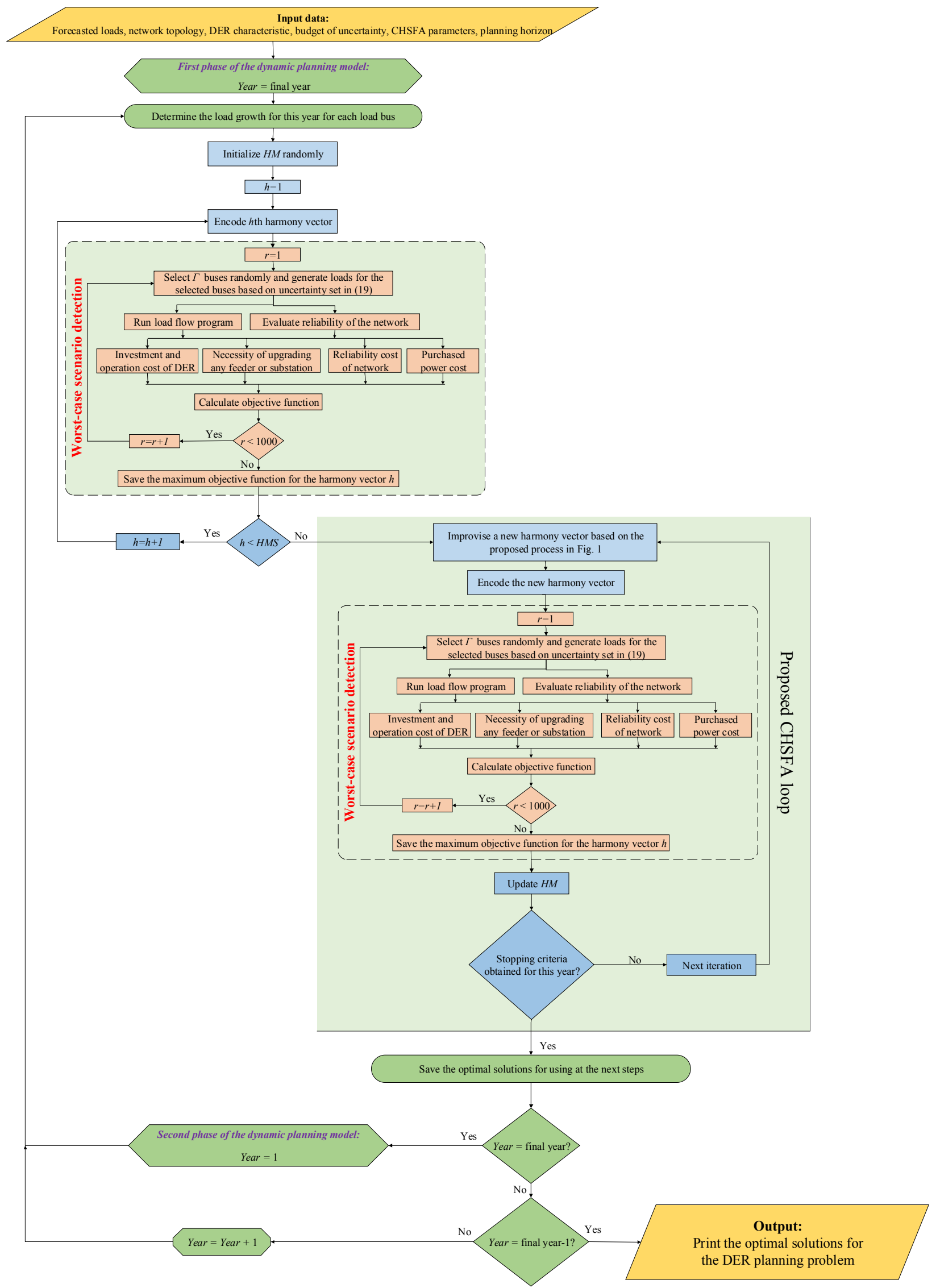

Fig. 2. The procedure of the proposed CHSFA to solve the dynamic robust DER planning problem 


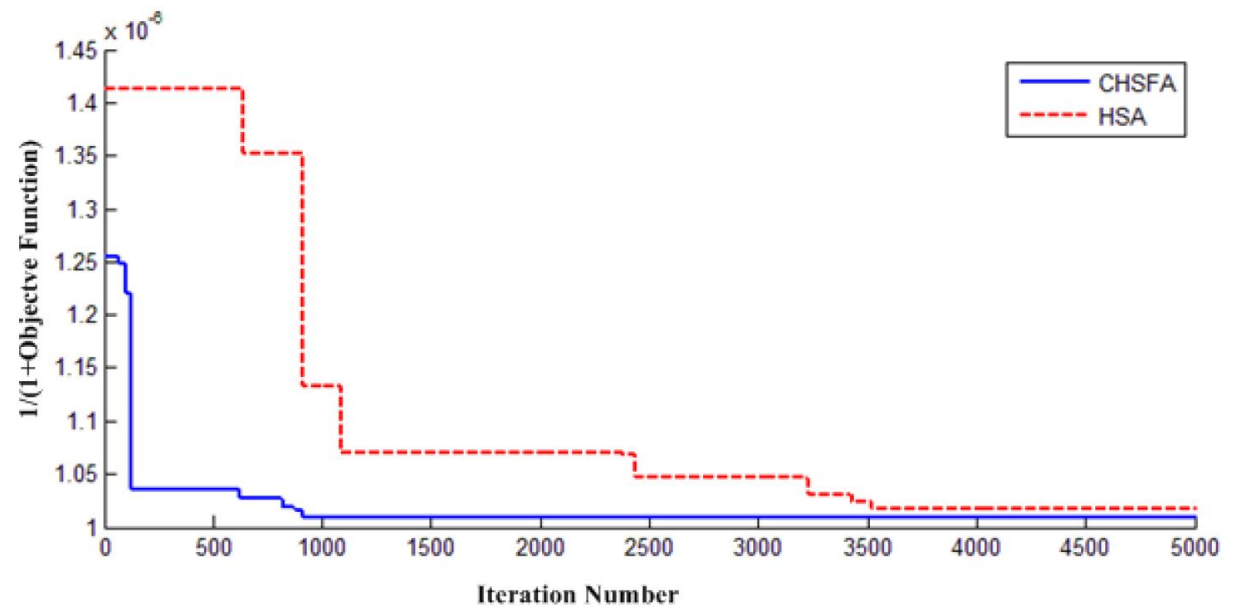

Fig. 3. Objective function values according to the iteration number for the first year planning

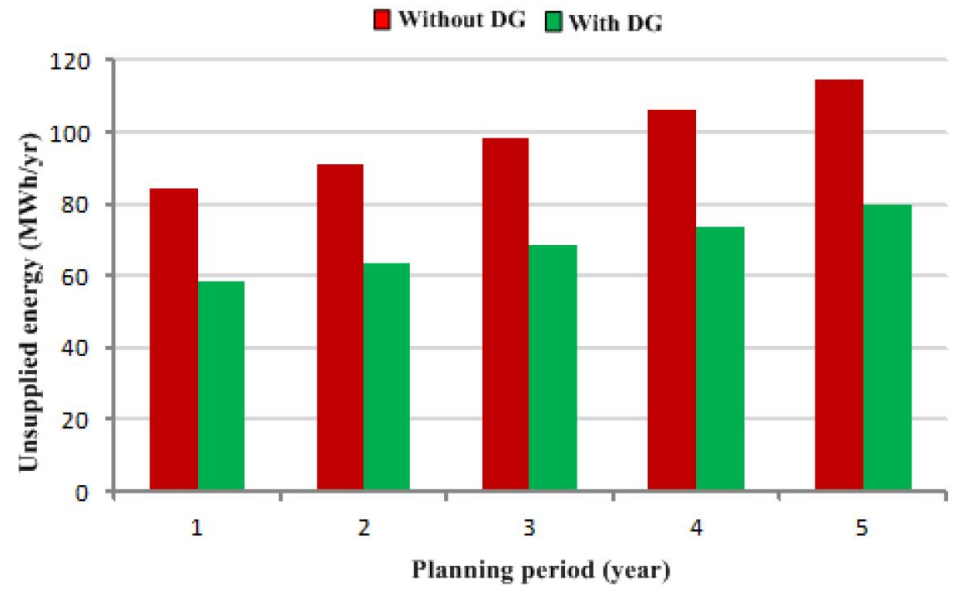

Fig. 4. Unsupplied energy in the network for the two planning cases 


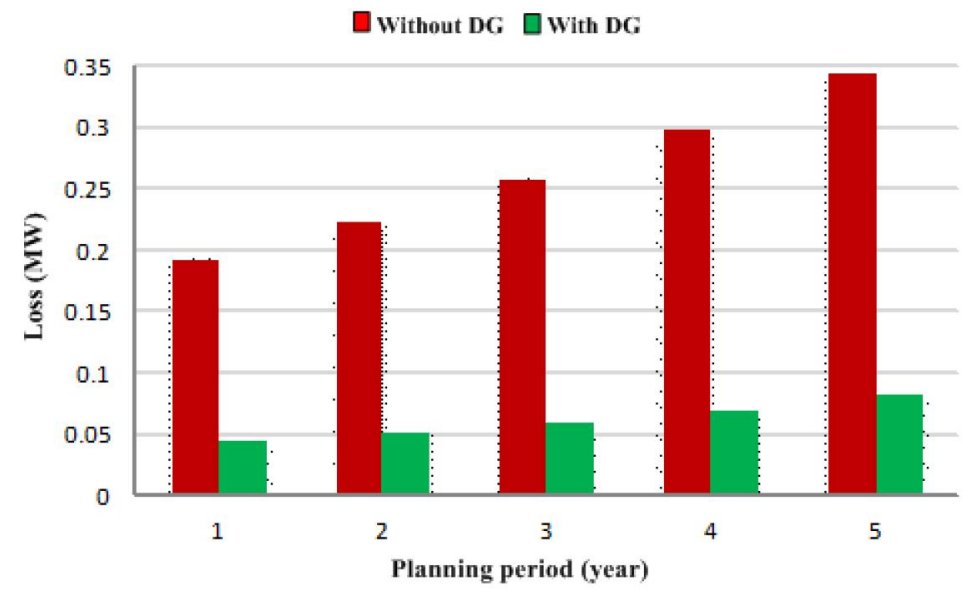

Fig. 5. Network loss for the two planning cases

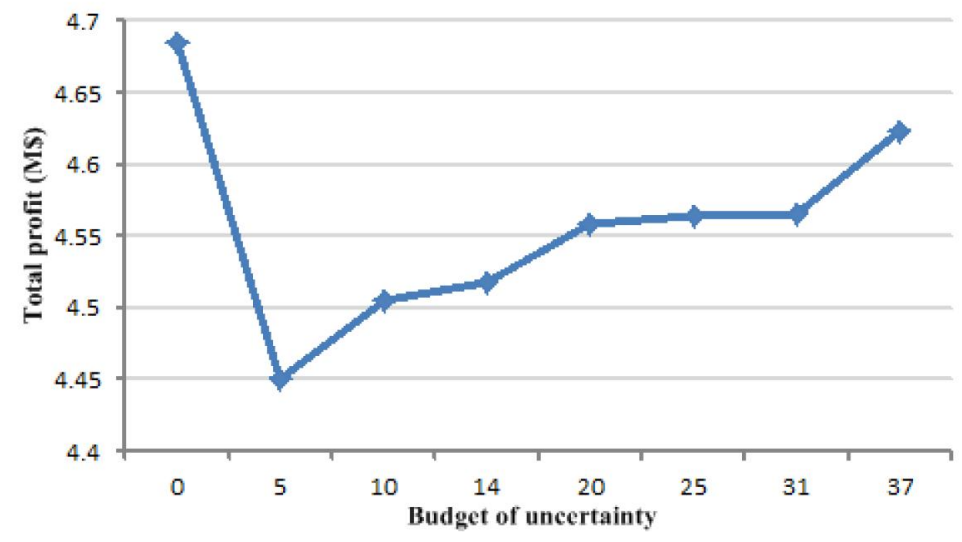

Fig. 6. Net present value of total profit according to the variation of budget of uncertainty 


\section{Appendix A:}

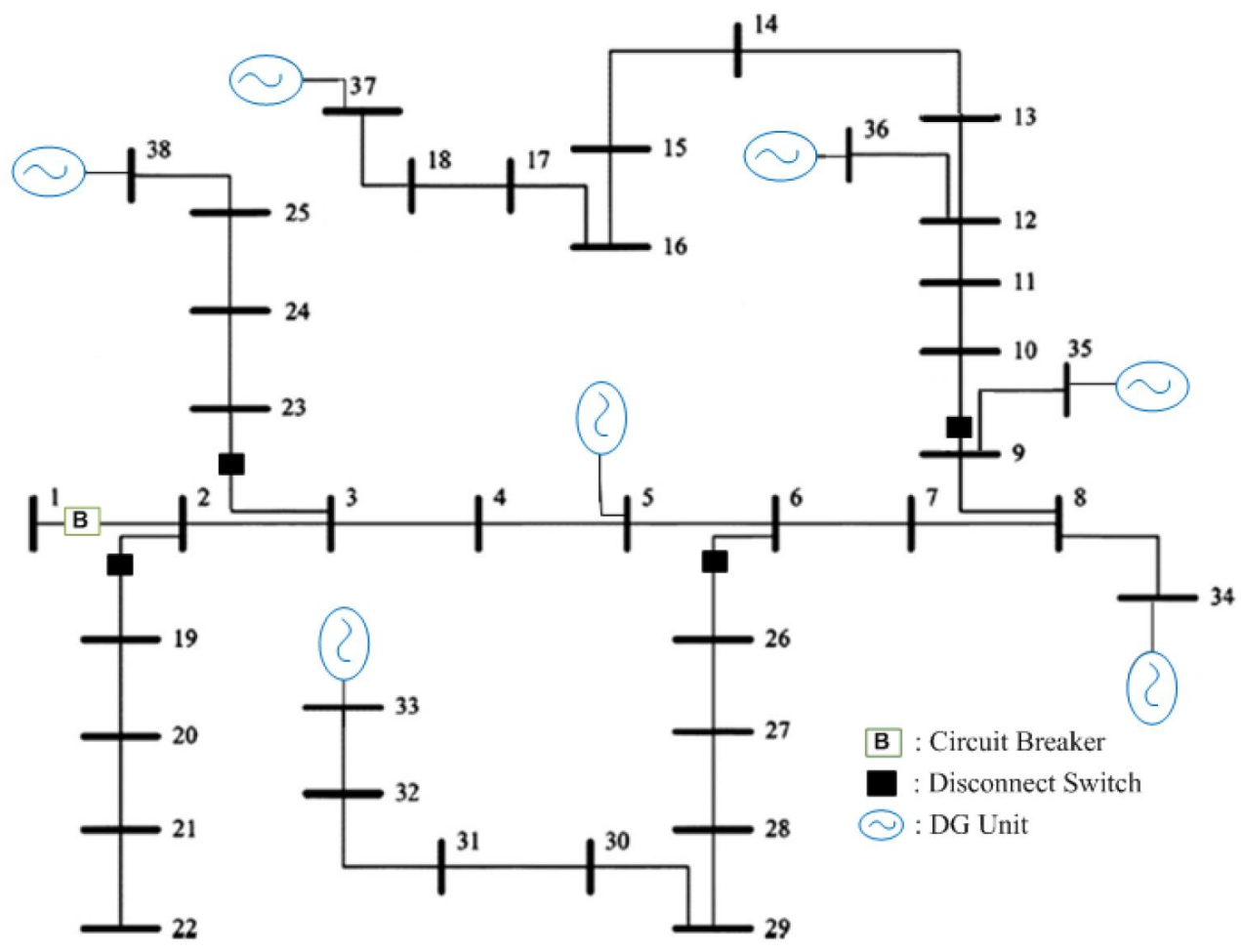

Fig. A. The 38-bus distribution test network

Table A. Technical/cost parameters of case study

\begin{tabular}{ccc}
\hline Parameter & Unit & Value \\
\hline Grid electricity price & $\$ / \mathrm{MWh}$ & 70 \\
New transformer cost & $\mathrm{M} \$$ & 0.05 \\
Feeder upgrading cost & $\mathrm{M} \$ / \mathrm{km}$ & 0.15 \\
DER investment cost & $\mathrm{M} \$ \mathrm{MVA}$ & 0.5 \\
DER O\&M cost & $\$ / \mathrm{MWh}$ & 50 \\
Discount rate & $\%$ & 12.5 \\
Annual load growth rate & $\%$ & 8 \\
Allowed voltage deviation & $\%$ & 5 \\
Project lifetime & year & 30 \\
Planning period & year & 5 \\
\hline
\end{tabular}


Table B. Reliability cost and customer price for the case study

\begin{tabular}{ccc}
\hline Load type & $\begin{array}{c}\text { Cost of not supplied energy } \\
(\$ / \mathrm{kWh})\end{array}$ & $\begin{array}{c}\text { Price of customer electricity } \\
(\mathbb{C} / \mathrm{kWh})\end{array}$ \\
\hline Industrial & 11.05 & 7 \\
Residential & 0.105 & 11.8 \\
Commercial & 3.6 & 10.4 \\
\hline
\end{tabular}

